\title{
An Integrated Decision-Making Approach for Green Supplier Selection in an Agri-Food Supply Chain: Threshold of Robustness Worthiness
}

\author{
Erfan Babaee Tirkolaee ${ }^{1,+} \mathbb{D}$, Zahra Dashtian ${ }^{2,+}$, Gerhard-Wilhelm Weber ${ }^{3,4,+} \mathbb{D}$, Hana Tomaskova ${ }^{5, *,+}$ TD $^{\text {, }}$ \\ Mehdi Soltani $^{2,+}$ and Nasim Sadat Mousavi ${ }^{6,+}$
}

1 Department of Industrial Engineering, Istinye University, Istanbul 34010, Turkey; erfan.babaee@istinye.edu.tr

2 Department of Industrial and Mechanical Engineering, Qazvin Islamic Azad University, Qazvin 45617, Iran; z.dashtian95@gmail.com (Z.D.); mehdisoltani618@gmail.com (M.S.)

3 Faculty of Engineering Management, Poznan University of Technology, 60-965 Poznan, Poland; gerhard.weber@put.poznan.pl

4 Institute of Applied Mathematics, Middle East Technical University, Ankara 06800, Turkey

5 Faculty of Informatics and Management, University of Hradec Kralove, 50003 Hradec Kralove, Czech Republic

6 Faculty of Management and Economics, Sharif University of Technology, Tehran 14588-89694, Iran; nasim.mousavi1993@gmail.com

* Correspondence: hana.tomaskova@uhk.cz

+ These authors contributed equally to this work.

\section{check for} updates

Citation: Tirkolaee, E.B.; Dashtian, Z.; Weber, G.-W.; Tomaskova, H.; Soltani, M.; Mousavi, N.S. An Integrated Decision-Making Approach for Green Supplier Selection in an Agri-Food Supply Chain: Threshold of Robustness Worthiness. Mathematics 2021, 9, 1304. https://doi.org/ $10.3390 /$ math9111304

Academic Editor: Frank Werner

Received: 6 May 2021

Accepted: 4 June 2021

Published: 7 June 2021

Publisher's Note: MDPI stays neutral with regard to jurisdictional claims in published maps and institutional affiliations.

\section{Copyright: (c) 2021 by the authors.} Licensee MDPI, Basel, Switzerland. This article is an open access article distributed under the terms and conditions of the Creative Commons Attribution (CC BY) license (https:// creativecommons.org/licenses/by/ $4.0 /)$.

\begin{abstract}
Along with the increased competition in production and service areas, many organizations attempt to provide their products at a lower price and higher quality. On the other hand, consideration of environmental criteria in the conventional supplier selection methodologies is required for companies trying to promote green supply chain management (GSCM). In this regard, a multi-criteria decision-making (MCDM) technique based on analytic hierarchy process (AHP) and fuzzy technique for order of preference by similarity to ideal solution (TOPSIS) is used to evaluate and rate the suppliers. Then, considering the resource constraint, weight of criteria and a rank of suppliers are taken into account in a multi-objective mixed-integer linear programming (MOMILP) to determine the optimum order quantity of each supplier under uncertain conditions. To deal with the uncertain multi-objectiveness of the proposed model, a robust goal programming (RGP) approach based on Shannon entropy is applied. The offered methodology is applied to a real case study from a green service food manufacturing company in Iran in order to verify its applicability with a sensitivity analysis performed on different uncertainty levels. Furthermore, the threshold of robustness worthiness (TRW) is studied by applying different budgets of uncertainty for the green service food manufacturing company. Finally, a discussion and conclusion on the applicability of the methodology is provided, and an outlook to future research projects is given.
\end{abstract}

Keywords: green supplier selection; order allocation; agri-food supply chain; robust goal programming; AHP-fuzzy TOPSIS; threshold of robustness worthiness (TRW)

\section{Introduction}

\subsection{Aim and Originality of the Study}

In a competitive environment, supplier selection is one of the most important problems that manufacturing firms encounter. In some industries, the cost of raw materials constitutes a high portion of the final production cost that can be minimized by selecting the appropriate supplier [1]. The supply chain is defined as a network of units for producing and delivering products and services that starts with the supplier or suppliers and ends with the warehouses and buying centers. Supply chain management (SCM) is a set of methods applied for effective integrating of suppliers, producers, warehouses and buying 
centers to supply the customers with the required products, at the identified quantity, and in a certain time and place in such a way that the total cost of the chain is minimized, and the customers are satisfied with a high service level. The major objective of any supply chain is to maximize the total value created. Regarding the governmental regulations and increased social awareness about conserving the environment, the manufacturing firms cannot neglect the environmental issues if they want to maintain their competitive advantage and become global firms. Increasing environmental concerns makes it necessary to highlight the subject of environmental pollutions involved in the industrial development of the supply chain activities and, in turn, results in the newly emerged concept of green supply chain management (GSCM) [2]. GSCM is the integrator of SCM with the environmental requirements over all stages of product design, raw material selection and supply, production and manufacturing, distribution and shipment processes, delivery to customers and, finally, after product consumption, recycling management in order to maximize the productivity of energy and resource consumption and improve the productivity of the whole supply chain. GSCM includes the process of supplying raw material, production, logistics management, distribution and service, consumption and recycling [3].

Supplier selection is one of the well-known activities that directly results in the determination of product quality and performance of the organization, and, consequently, the efficiency of the supply chain [4]. It has a large impact on the whole supply chain, and it is so important not to keep a focus on value of the supplier selection in the entire procurement level. It is known as the key stage where we recognize, assess, and choose our suppliers. The main questions to be answered in light of supplier selection include:

i. Are we selecting the optimal suppliers?

ii. Are we paying the best price for the products?

iii. Are we adding value to our company?

The recommendation is to have a framework for green supplier selection (GSS) that consists of four main phases: 1 . having a clear definition of the problem; 2 . formulating the criteria for guiding the selection: the buyer must convert their need to the decision-making criteria; 3. reducing the initial set of suppliers by categorizing the potential suppliers according to the quality measures; 4 . the final selection which is performed in the selection process based on the rankings [5]. Thus, the organizations must consider the environment management over the whole life cycle of their products to be assured of improving the environmental performance of the supply chain. Supplier selection in agri-food supply chains is very critical in terms of perishability and vulnerability of agricultural products as well as stakeholders' engagement [6], and the quality of the products can be guaranteed by taking into account the safety, perishability and sustainability requirements [7]. Moreover, considering environmental and greenness issues is important, such as other supply chains, which can be followed as green supplier selection in agri-food supply chains.

\subsection{Research Background}

There are many research works performed on GSCM and GSS in the literature using mathematical models and multi-criteria decision-making (MCDM) techniques [8-17]. In the following, some of these recent works are reviewed with special attention to agri-food GSCM. Dickson [18] can be regarded as one of the pioneers in supplier evaluation. He considered 23 criteria for the supplier performance evaluation, including quality, on-time delivery and performance history as three important criteria. Lin [19] developed an integrated model of the fuzzy analytical network process (FANP) and multi-objective linear programming (MOLP) model for supplier selection problem. On the first stage of his suggested model, the factors were weighted and rated, and then vagueness and uncertainty were included in the model, applying the fuzzy theory. On the second stage, the issues of supplier selection and optimum order allocation were addressed in their mathematical model. They proposed four objective functions of minimization type (total cost, delivery lateness and number of defective products purchased) and maximization type (total purchase value), respectively. Kannan et al. [20] proposed a hybrid approach based on 
FANP, fuzzy technique for order of preference by similarity to ideal solution (TOPSIS) and a fuzzy MOLP model for supplier selection problem in a green supply chain. A comprehensive eco-friendly technique was introduced by Kumar et al. [21] for supplier selection. They proposed a data envelopment analysis (DEA) with carbon footprint monitoring to consider heterogeneous suppliers and regional emission compliance standards and laws. Bakeshlou et al. [22] addressed the problem of supplier selection using a multi-objective decision-making algorithm. They applied a hybrid fuzzy multi-objective decision-making (MODM) algorithm for a green supplier selection (GSS) problem considering 17 criteria. Rueda et al. [23] proposed a method that was a synthesis of the widely applied instruments applied by agri-food companies for the sustainability promotion of their supply chains. This method also provided an analytical framework to elucidate how the decisions are made. This framework was based on the competitive environment in which firms operate with respect to the location of the raw material, technologies of the suppliers, leverage over upstream suppliers and the characteristics of the end-markets. Shi et al. [24] introduced a novel technique for GSS with interval-valued intuitionistic uncertain linguistic (IVIUL) information. They applied grey relational analysis (GRA) and TOPSIS methods for the assessment and selection of green suppliers. Finally, a case study in an agri-food industry was conducted to demonstrate the applicability of their proposed methodology.

As relevant research carried out with emphasis on operations research (OR) methods for a sustainable agri-food supply chain, Allaoui et al. [25] presented a two-stage hybrid methodology. On the first stage, they implemented AHP and ordered weighted averaging (OWA) aggregation method. Based on the obtained results at the first stage, a multiobjective mathematical model was developed at the second stage to optimize the design of the supply chain network. Banaeian et al. [13] compared the application of three popular multi-criteria supplier selection methods in a fuzzy environment. The incorporation of fuzzy set theory into TOPSIS, VlseKriterijuska Optimizacija I Komoromisno Resenje (VIKOR) and GRA methods was thoroughly discussed. The methods were then utilized to complete a green supplier evaluation and selection study for an actual company from the agri-food industry. Their comparative analysis for the case study indicated that the three fuzzy methods arrive at identical supplier rankings, while fuzzy GRA requires less computational complexity to generate the same results. Gören [26] presented a decision framework for sustainable supplier selection and order allocation in a case study problem. Their framework consists of three integrated components. First, a fuzzy decision-making trial and evaluation laboratory (DEMATEL) helps to identify the weights of sustainable criteria. Second, these weights are considered as inputs in Taguchi Loss Functions for ranking and calculating the rating value of each supplier. Finally, the ranking values were treated as inputs of a bi-objective optimization program to determine the optimal order quantities that should be allocated to each supplier. Liu et al. [27] suggested a novel two-stage integrated model for a GSS problem of fresh product. At the first stage, they took function development (QFD), customer requirement (CR) and company strategy (CS) into account as selection criteria. A fuzzy best-worst method (BWM) was applied to obtain the criteria weights. To rank the suppliers, a fuzzy multi-objective optimization by ratio analysis (MOORA) plus the full multiplicative form, namely, MULTIMOORA was then employed. Recently, Haeri and Rezaei [28] introduced a grey-based GSS model to cover uncertain environments. They applied a novel weight assignment model using the combination of BWM and fuzzy grey cognitive map to obtain the interdependencies among the economic and environmental criteria. They could finally demonstrate the efficiency of the proposed method by analyzing a real case study. Recently, Tirkolaee et al. [29] proposed a hybrid approach based on fuzzy MCDM and weighted goal programming (WGP) to tackle a sustainable-reliable supplier selection problem. They investigated a real case study problem in the lamp supply chain and demonstrated the efficiency of their methodology to determine the optimal policy. Keshavarz-Ghorabaee et al. [30] offered an integrated decision-making approach based on Fermatean fuzzy sets, weighted aggregated sum 
product assessment (WASPAS) and the simple multi-attribute rating technique (SMART) for evaluating and selecting green construction suppliers under uncertainty.

Table 1 provides a comparison of similar supplier selection problems in order to highlight the contributions research has made.

Table 1. Brief literature review.

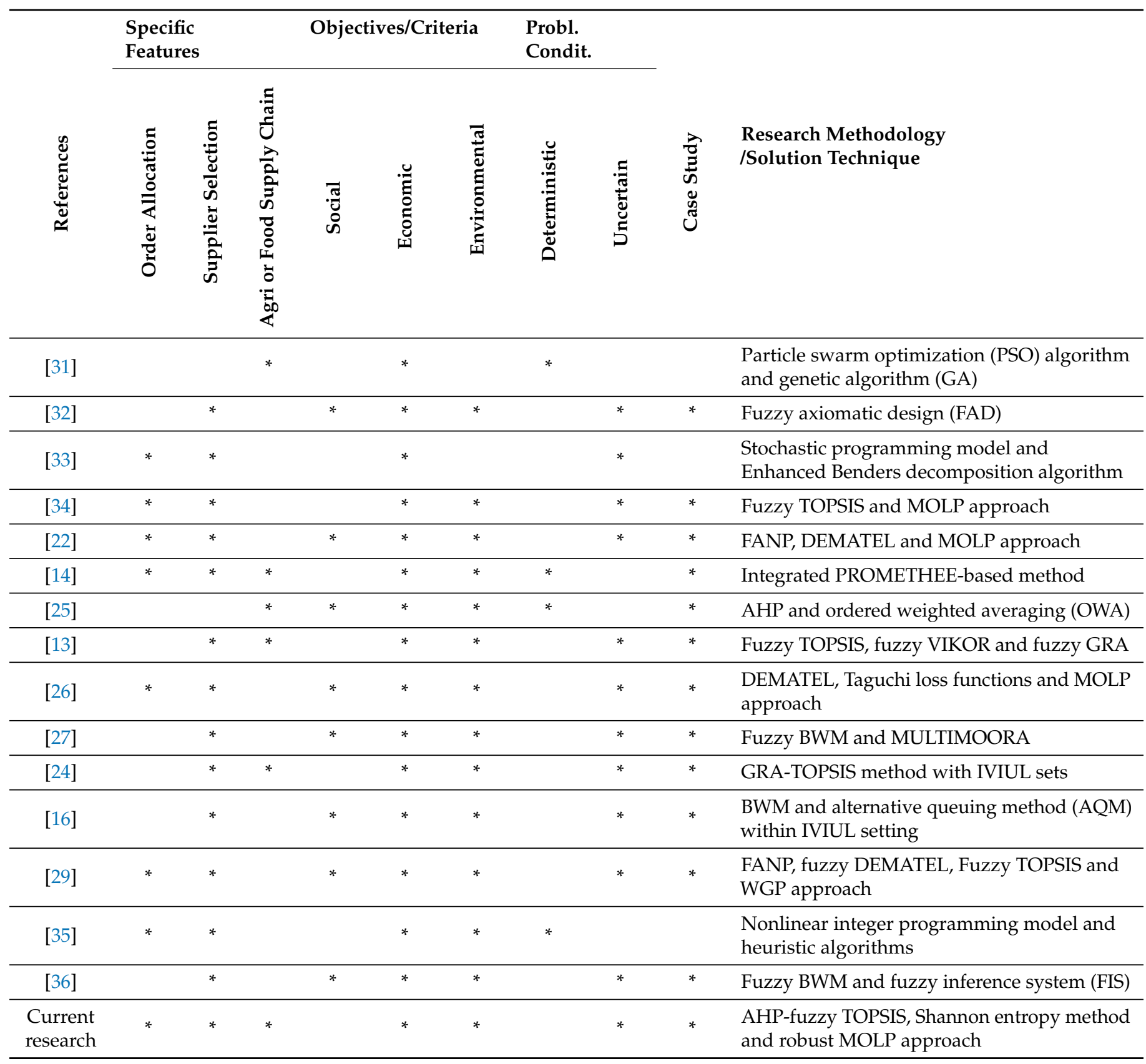

\subsection{Contributions and Structure of the Manuscript}

According to the literature, only a few studies have been practically developed in which there were hybrid methods of economy and GSS criteria, and attention to the order allocation and the supplier selection problem in a green agri-food supply chain. Moreover, the robust optimization technique was not investigated in the literature on our subject. Thus, the innovation of our paper is summarized as follows: 
1. Applying a AHP-fuzzy TOPSIS method for rating the suppliers in a green agri-food supply chain network;

2. Developing a robust goal programming (RGP) model to determine the order allocation under uncertain condition;

3. Introducing and investigating the threshold of robustness worthiness (TRW);

4. Investigating the applicability of the proposed methodology through an illustrative case study.

The rest of the paper is organized as follows. Sections 2 and 3 present the proposed methodology to design a green agri-food supply chain design. An AHP- fuzzy TOPSIS method is introduced in Section 2, followed by the RGP-based mathematical model in Section 3 to deal with uncertainty and multi-objectiveness. The computational results of the case study problem are explained in Section 4. A discussion of the results is provided in Section 5 and, finally, Section 6 concludes the work with a note about future research directions.

\section{Methodology}

In this section, the proposed integrated approach for GSS is presented based on AHPfuzzy TOPSIS and RGP. The analytic hierarchical process (AHP) is used for the calculation of relative weights of the supplier selection criteria; the fuzzy TOPSIS is used for rating the suppliers according to the selection criteria; finally, the weight of each supplier is identified. Then, the problem is formulated as a bi-objective model based on real-world assumptions and limitations, in order to determine the optimal values of the decision variables, which are described in Section 3. To cope with two objectives of the problem under uncertainty of the demand parameter, an RGP technique is applied to the model. This technique guarantees feasibility, robustness and optimality of the solutions [37]. Figure 1 depicts the proposed method.

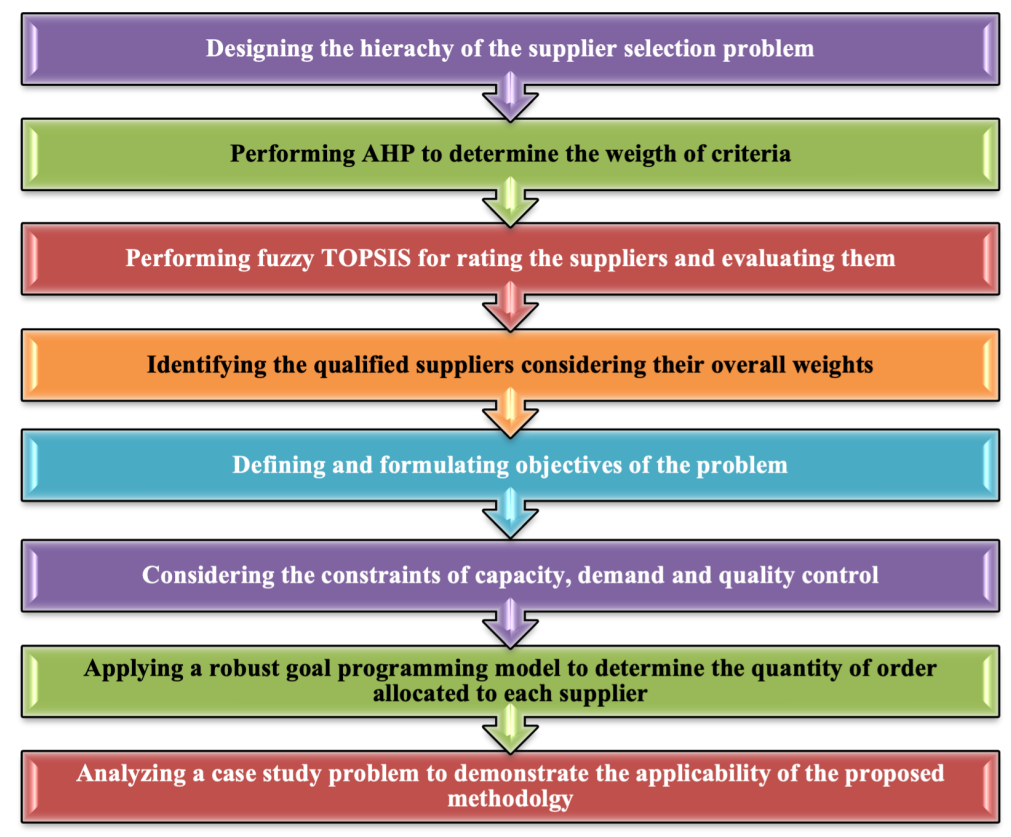

Figure 1. A solution procedure for the proposed model of supplier selection and order allocation.

\subsection{Analytic Hierarchical Process (AHP)}

The AHP technique helps decision-makers to identify the alternative that best befits their goals. It was first introduced by Saaty [38] as a measurement theory to provide pairwise comparisons, which depend on expert opinions.

AHP is implemented in four decision-making phases: 1. designing the hierarchy, 2. performing the pairwise comparisons, 3. calculating the weights, and system consistency. 


\subsubsection{Phase 1: The Hierarchy Tree Construction}

The phase 1, important criteria of decision making must be hierarchically expressed in the form of a decision tree where each criterion can include several sub-criteria.

\subsubsection{Phase 2: Pairwise Comparisons}

The criteria of each level of the AHP are compared with the ones of the upper level in a pairwise manner, and their weights are calculated. They are called relative weights. These weights are then combined and identify the final weight of each solution. These comparisons are given by decision makers as linguistic variables; i.e., if criterion $i$ is compared to criterion $j$, the decision maker expresses the importance of $i$ over $j$ as one of the following choices based on Saaty's nine-point scale (cf. Table 2):

Table 2. Comparison criteria according to the relative importance degree.

\begin{tabular}{ll}
\hline $\begin{array}{l}\text { Relative Comparison of Criterion } i \text { Against } j \\
\text { (Regarding the Intended Goal) }\end{array}$ & Relative Importance Degree (Score) \\
\hline Equal importance & 1 \\
Weak priority of $i$ against $j$ & 3 \\
Strong priority of $i$ against $j$ & 5 \\
Very strong priority of $i$ against $j$ & 7 \\
Absolute priority of $i$ against $j$ & 9 \\
\hline
\end{tabular}

Now, a pairwise comparison matrix is generated employing Saaty's nine-point scale. Considering $\mathrm{n}$ criteria, we can construct a square matrix ( $A$ applying the pairwise comparison of criterion $i$ with criterion $j$ ), which is shown in Equation (1), where $a_{i j}$ represents the importance of $i$ th criterion against $j$ th criterion. We have $a_{i j}=1$, when $i=j$, and $a_{j i}=\frac{1}{a_{i j}}$ :

$$
A=\left[\begin{array}{ccc}
a_{11} & \cdots & a_{1 n} \\
\vdots & \ddots & \vdots \\
a_{n 1} & \cdots & a_{n n}
\end{array}\right]
$$

\subsubsection{Phase 3: The Extraction of Weights from the Pairwise Comparison Matrix}

The weight extraction method depends on the consistency or inconsistency of the decision matrix. Since decision makers are not always consistent, AHP technique permits some small opinion inconsistency. If the condition represented in Equation (2) holds, then the matrix is called consistent:

$$
a_{i j} \times a_{j k}=a_{i k} ; \forall i, j, k .
$$

For further information, please see Saaty and Vargas [39].

\subsection{Similarity to the Ideal Solution}

In the real world, due to incomplete or inaccessible information, data are not deterministic; they are, as we say, fuzzy data. Actually, in many issues, unclear and unrealistic concepts are observed in the decision-making data; deterministic data are not sufficiently appropriate in real conditions. Therefore, we applied TOPSIS with fuzzy data to prioritize the potential suppliers. In this method, the ranking of solutions and the criteria relative weights have been given by linguistic variables whose corresponding fuzzy numbers are presented in Table 3. 
Table 3. Fuzzy numbers for evaluating the criteria.

\begin{tabular}{cc}
\hline Linguistic Variable & Corresponding Fuzzy Number \\
\hline Very Low (VL) & $(0,0,1)$ \\
Low (L) & $(0,1,3)$ \\
Medium Low (ML) & $(1,3,5)$ \\
Medium (M) & $(3,5,7)$ \\
Medium High (MH) & $(5,7,9)$ \\
High (H) & $(7,9,10)$ \\
Very High (VH) & $(9,10,10)$ \\
\hline
\end{tabular}

In this technique, the decision matrix contains $m$ rows and $n$ columns. Subsequently, six steps of the fuzzy TOPSIS technique are outlined.

\subsubsection{Step 0: Creating the Decision Matrix}

Considering the number of criteria and solutions, the decision matrix is created as follows: $x_{i j}$ is the performance of the alternative $i(i=1,2, \ldots, m)$ in relation to the criterion $j(j=1,2, \ldots, n)$. In this matrix, shown in Equation (3), the criterion that has a positive utility is the profit criterion, and the criterion that has a negative utility is the cost criterion. Furthermore, the importance degree of each criterion in the decision making has to be identified in this step, which is represented by $\widetilde{W}=\left(w_{j 1}, w_{j 2}, w_{j 3}\right)$-a fuzzy factor. Now, the fuzzy decision matrix $(\widetilde{D})$ is defined as follows, which comes from the potential use of eigenproblem [40,41]:

$$
\widetilde{D}=\begin{array}{ccccc}
X_{1} & \cdots & X_{j} & \cdots & X_{n} \\
A_{1} \\
\vdots \\
A_{i} \\
\vdots \\
A_{m}
\end{array}\left[\begin{array}{ccccc}
\widetilde{x}_{11} & \cdots & \widetilde{x}_{1 j} & \cdots & \widetilde{x}_{1 n} \\
\vdots & & \vdots & & \vdots \\
\widetilde{x}_{i 1} & \cdots & \widetilde{x}_{i j} & \cdots & \widetilde{x}_{i n} \\
\vdots & & \vdots & & \vdots \\
\widetilde{x}_{m 1} & \cdots & \widetilde{x}_{m j} & \cdots & \widetilde{x}_{m n}
\end{array}\right]
$$

where $X_{j}$ denotes the fuzzy performance vector of all solutions for criterion $j$, and $A_{i}$ represents the fuzzy performance vector of all criteria for alternative $i$.

\subsubsection{Step 1: Normalizing the Decision Matrix}

In this step, the values of the decision matrix become unscaled by normalization. Consequently, the normalized fuzzy decision matrix $(\widetilde{R})$ is defined:

$$
\widetilde{R}=\left[\widetilde{r}_{i j}\right]_{m \times n}(i=1,2, \cdots, m ; j=1,2, \cdots, n),
$$

with respect to $\widetilde{r}_{i j}=\left(\frac{a_{i j}}{c_{j}^{+}}, \frac{b_{i j}}{c_{j}^{+}}, \frac{c_{i j}}{c_{j}^{+}}\right)$and $c_{j}^{+}=\max \left(c_{i j}\right)$ for positive criteria, $\widetilde{r}_{i j}=\left(\frac{a_{j}^{-}}{c_{i j}}, \frac{a_{j}^{-}}{b_{i j}}, \frac{a_{j}^{-}}{a_{i j}}\right)$ and $a_{j}^{-}=\min \left(a_{i j}\right)$ for negative criteria, where $a_{i j}, b_{i j}, c_{i j}$ are three elements of the triangular fuzzy number for rating alternative $i$ with respect to criterion $j$.

\subsubsection{Step 2: Weighted Normalized Decision Matrix}

Considering different criteria, the weighted fuzzy decision matrix is obtained by multiplying the normalized fuzzy decision matrix by the importance coefficient of each criterion:

$$
\widetilde{V}=\left[\widetilde{v}_{i j}\right]_{m \times n}(i=1,2, \cdots, m ; j=1,2, \cdots, n),
$$

with respect to $\widetilde{v}_{i j}=\widetilde{r}_{i j} \otimes \widetilde{W}_{j}(i=1,2, \cdots, m ; j=1,2, \cdots, n)$, where $\widetilde{W}_{j}$ represents the importance coefficient of criterion $j$. 
2.2.4. Step 3: Finding the Fuzzy Positive Ideal Solution and Fuzzy Negative Ideal Solution

First, $M\left(\widetilde{v}_{i j}\right)$ is used to compare fuzzy numbers-the mean of removals is calculated in the following way:

$$
M\left(\widetilde{v}_{i j}\right)=\frac{-a_{i j}^{2}-a_{i j} b_{i j}+b_{i j} c_{i j}+c_{i j}^{2}}{3\left(c_{i j}-a_{i j}\right)}(i=1,2, \cdots, m ; j=1,2, \cdots, n) .
$$

The maximum value of $M\left(\widetilde{v}_{i j}\right)$ is selected as the fuzzy positive ideal solution (FPIS) for the $j$ th criterion $\widetilde{V}_{j}^{+}$; it is represented as $\widetilde{V}_{j}^{+}=\left(a^{+}, b^{+}, c^{+}\right)$. The minimum value of $M\left(\widetilde{v}_{i j}\right)$ is regarded as the fuzzy negative ideal solution (FNIS) for the $j$ th criterion $\widetilde{V}_{j}^{-}$, and it is represented as $\widetilde{V}_{j}^{-}=\left(a^{-}, b^{-}, c^{-}\right)$.

\subsubsection{Step 4: Calculating the Distance of Solutions from the FPIS and FNIS}

The distances of solutions from the FPIS and FNIS or fuzzy positive ideal reference point $\left(D_{i j}^{+}\right)$and fuzzy negative ideal reference point $\left(D_{i j}^{-}\right)$are calculated according to Equations (7) and (8):

$$
\begin{aligned}
D_{i j}^{+}=d\left(\widetilde{v}_{i j}, \widetilde{v}_{j}^{+}\right)= & \sqrt{\frac{1}{3}\left(a_{i j}-a^{+}\right)^{2}+\left(b_{i j}-b^{+}\right)^{2}+\left(c_{i j}-c^{+}\right)^{2},} \\
& (i=1,2, \cdots, m ; j=1,2, \cdots, n) . \\
D_{i j}^{-}=d\left(\widetilde{v}_{i j}, \widetilde{v}_{j}^{-}\right)= & \sqrt{\frac{1}{3}\left(a_{i j}-a^{-}\right)^{2}+\left(b_{i j}-b^{-}\right)^{2}+\left(c_{i j}-c^{-}\right)^{2}}, \\
& (i=1,2, \cdots, m ; j=1,2, \cdots, n) .
\end{aligned}
$$

Here, $\left(D_{i j}^{+}\right)$and $\left(D_{i j}^{-}\right)$are deterministic numbers. The distances of the solution $i$ from the positive ideal solution $\left(S_{i}^{+}\right)$and negative ideal solution $\left(S_{i}^{-}\right)$are determined by Equations (9) and (10), respectively:

$$
\begin{aligned}
& S_{i}^{+}=\sum_{j=1}^{n} D_{i j}^{+},(i=1,2, \cdots, m), \\
& S_{i}^{-}=\sum_{j=1}^{n} D_{i j}^{-}, \quad(i=1,2, \cdots, m) .
\end{aligned}
$$

2.2.6. Step 5: Calculating the Similarity Index

The similarity index or closeness coefficient of each alternative $\left(C_{i}\right)$ is defined by:

$$
C_{i}=\frac{S_{i}^{-}}{S_{i}^{+}+S_{i}^{-}}, \quad(i=1,2, \cdots, m) .
$$

\subsubsection{Step 6: Ranking the Solutions}

The calculated similarity indices are ranked in descending order.

\subsection{Robust Goal Programming (RGP)}

The RGP approach is implemented to deal with the uncertainty and bi-objectiveness of the model. To the best of our knowledge, RGP has not been investigated enough in the literature while it is regarded as an efficient exact solution approach [37,42]. In other words, it consists of two efficient methods; i.e., GP that causes the constraints to be less strict and the solution space to be larger [43], and robust optimization that protect the solutions against worst-case realizations of the uncertain parameters [44]. Hence, we apply RGP to the model in order to generate robust solutions and guarantee the feasibility of the solutions under uncertain conditions. 


\section{The Robust Goal Programming Mathematical Model}

The aim of this stage is to design a novel mathematical model based on the real-world assumptions in order to determine the optimal allocation of raw material to the suppliers within a green agri-food supply chain design so that total cost (cf. Equation (21)) and total weighted purchase (cf. Equation (22)) are minimized and maximized, respectively. This model is applied to allocate orders to the selected suppliers that have been prioritized according to the proposed technique in Section 2.

Here, a two-objective linear programming model is proposed for the supplier selection problem with multiple sourcing that minimizes the final purchasing costs and maximizes the total purchasing amount from the high-ranked suppliers considering their priority values. Of course, this model includes a set of constraints such as purchasing order, supplier capacity and assumptions applied in formulating the multi-criteria linear programming model. The number of items allocated to a supplier is also taken into account. The order quantity of each item from a supplier is constrained by the supplier capacity, too.

\subsection{Interval-Based Robust Optimization}

There are different methods to deal with the uncertainty. In this paper, the intervalbased robust optimization method based on the Bertsimas and Sim model is used, because it offers a linear model that outperforms the others [45,46]. Accordingly, the demand parameter $\left(D_{r}\right)$ is considered uncertain; i.e., it is defined as the interval $\left[\bar{D}_{r}-\widehat{D}_{r}, \bar{D}_{r}+\widehat{D}_{r}\right]$ in which $\bar{D}_{r}$ is the average demand of item $r$, and $\widehat{D}_{r}$ is the deviation rate of demand of item $r$. Here, $\widehat{D}_{r}$ is defined according to the uncertainty level $(\psi)$, determined by $\widehat{D}_{r}=\psi \bar{D}_{r}$. This parameter leads to uncertainty in the maximum acceptable defect rate and constraint and the calculation equation of the order quantity. The corresponding equations with uncertainty are:

$$
\begin{gathered}
\sum_{s=1}^{S} q_{r s} x_{r s} \leq Q_{r} D_{r}, \quad(r=1,2, \cdots, R), \\
\sum_{s=1}^{S} x_{r s}=D_{r}-l_{r}, \quad(r=1,2, \cdots, R),
\end{gathered}
$$

where $q_{r s}$ and $Q_{r}$ represent the average defect rate of item $r$ from supplier $s$ and maximum acceptable defect rate of item $r$, respectively. Then, the parameter $\Gamma$ (uncertainty budget) is defined for the $r$ th item such that $\Gamma_{r} \in\left[0,\left|J_{r}\right|\right]$, where $J_{r}$ represents the set of coefficients in row $r$ of the constraints; Equations (12) and (13) [46]. In fact, it ensures the robustness adjustment against the protection level of the solution. Bertsimas and Sim [46] demonstrated that it is unlikely that all of the coefficients change concurrently. In fact, a subset of the coefficients is allowed to have an impact on the solution adversely. On the other hand, due to the symmetric distribution of variables, even if more than the parameters change, the obtained robust solution will remain feasible with a very high probability. Therefore, this is called the conservation level for each item. The parameter may be an integer or not. If so, then, the problem will be deterministic. On the other hand, if Bertsimas' and Sim's approach is transformed to Soyster's method, then the most degree of conservation [46] is obtained. Thus, the fluctuation of the robustness is adjusted against the conservatism level of the solution.

Finally, the proposed linear robust form of Equation (12) is [47]:

$$
\sum_{s \in J_{r}} q_{r s} x_{r s} \leq Q_{r}\left(\bar{D}_{r}-\Gamma_{r}^{1} \widehat{D}_{r}\right), \quad(r=1,2, \cdots, R),
$$

where $\Gamma_{r}^{1}$ denotes the uncertainty budget associated with the demand uncertainty of $r$ th item in Equation (12), which can take value in $[0,1]$.

Similarly, Equation (13) would be robust as follows [48]:

$$
\left(\bar{D}_{r}-\Gamma_{r}^{2} \widehat{D}_{r}\right)-l_{r} \leq \sum_{s \in J_{r}} w_{r s} \leq\left(\bar{D}_{r}+\Gamma_{r}^{2} \widehat{D}_{r}\right)-l_{r}, \quad(r=1,2, \cdots, R),
$$


where $\Gamma_{r}^{2}$ denotes the uncertainty budget associated with the demand uncertainty of $r$ th item in Equation (13), which can take value in $[0,1]$.

Now, a robust mixed-integer linear goal programming (RMILGP) model is proposed to formulate the problem, based on the suggested robust model by Bertsimas and Sim [46].

\subsection{Objective Functions}

$$
\begin{aligned}
& \text { minimize Total costs }= \sum_{r=1}^{R} \sum_{s=1}^{S} p_{r s} x_{r s}+\sum_{r=1}^{R} \sum_{s=1}^{S} O_{r s} x_{r s}+\sum_{r=1}^{R} \sum_{s=1}^{S} t_{r} d_{s} x_{r s}+ \\
&+\sum_{r=1}^{R} \sum_{s=1}^{S} H_{r} x_{r s}+\sum_{r=1}^{R} B_{r} l_{r} \\
& \text { maximize Total purchasing value }=\sum_{r=1}^{R} \sum_{s=1}^{S} W_{r s} x_{r s}
\end{aligned}
$$

Equations (16) and (17) represent the 1st and 2nd objectives of our model, respectively. As is clear, the 1st objective is to minimize the total cost of the proposed green supply chain, and the 2nd objective is to maximize the total purchasing value obtained by different suppliers and food items.

\subsection{RGP Model}

$$
\begin{gathered}
\text { minimize }\left(W_{1}^{\prime} \frac{d l_{1}^{+}}{T C P}\right)+\left(W_{2}^{\prime} \frac{d l_{2}^{+}}{T V P}\right) \\
\text { subject to } \sum_{r=1}^{R} \sum_{s=1}^{S} p_{r s} x_{r s}+\sum_{r=1}^{R} \sum_{s=1}^{S} O_{r s} x_{r s}+\sum_{r=1}^{R} \sum_{s=1}^{S} t_{r} d_{s} x_{r s}+ \\
+\sum_{r=1}^{R} \sum_{s=1}^{S} H_{r} x_{r s}+\sum_{r=1}^{R} B_{r} l_{r}+d l_{1}^{-}-d l_{1}^{+}=T C P, \\
\sum_{r=1}^{R} \sum_{s=1}^{S} W_{r s} x_{r s}+d l_{2}^{-}-d l_{2}^{+}=T V P \\
\sum_{s \in J_{r}} q_{r s} x_{r s} \leq Q_{r}\left(\bar{D}_{r}-\Gamma_{r}^{1} \widehat{D}_{r}\right), \quad(r=1,2, \cdots, R) \\
\left(\bar{D}_{r}-\Gamma_{r}^{2} \widehat{D}_{r}\right)-l_{r} \leq \sum_{s \in J_{r}} x_{r s} \leq\left(\bar{D}_{r}+\Gamma_{r}^{2} \widehat{D}_{r}\right)-l_{r}, \quad(r=1,2, \cdots, R) \\
x_{r s} \leq c_{r s} y_{r s}, \quad(r=1,2, \cdots, R ; s=1,2, \cdots, S) \\
x_{r s} \geq c_{r s}^{\prime} y_{r s}, \quad(r=1,2, \cdots, R ; s=1,2, \cdots, S) \\
x_{r s}, l_{r} \geq 0, y_{r s} \in\{0,1\}, \quad(r=1,2, \cdots, R ; s=1,2, \cdots, S)
\end{gathered}
$$

Equation (18) denotes the main objective of the RGP model with the aim of minimizing the weighted sum of positive deviation from the 1st objective (cf. Equation (15)) and negative deviation from the 2nd objective (cf. Equation (16)). Since the 1st objective is a minimization function and the 2nd objective is a maximization one with different units, each related part in the RGP objective is divided by its ideal value in order to be normalized. Equation (19) considers the total cost that consists of the purchasing cost, ordering cost, transportation cost, holding cost and inventory shortage cost, which is written as a constraint using RGP. Objective (Equation (20)) focuses on the total weighted purchasing value, which is written as another constraint using RGP. Note that TCP and TVP 
are calculated by solving the single-objective model by 1st and 2nd objectives separately. Equation (21) is a robust constraint that limits the average defect rate of raw materials to the maximum acceptable defect rate. Equation (22) is another robust constraint with the same notations of robustness defines that the order quantity of item $r$ must be equal its total demand minus its quantity that is not fulfilled. Equation (23) guarantees that the total order quantity of item $r$ from supplier $s$ has to not exceed the capacity of item $r$. Equation (24) reflects that the order quantity of item $r$ from supplier $s$ must not be less than the minimum capacity of supplier $s$ (or, due to economic considerations, the order quantity of item $r$ from supplier $s$ must be higher than the minimum capacity of supplier $s$ ). Equation (25) indicates the type of the decision variables.

\section{Computational Analysis}

This section presents the results of a real case study in order to evaluate the applicability of the offered methodology; through supplier evaluation and selection process, the aim is to provide the Green Service Food Company in Iran with a clear image of the structure of activities performed by the purchasing and supply manager, with the hope that it can improve the economic performance and efficiency of the company. Investigating the list of effective factors on the supplier evaluation and selection process and interviewing the relevant experts of raw food material supply and food industry specialist, 10 major criteria of price, transportation cost, flexibility, technology, quality, on-time delivery, failure, order fulfillment, green competencies and environmental management system have been identified. It should be noted that the first eight criteria are regarded as conventional criteria [13], and the last two criteria are taken into account as the most important environmental criteria [49]. Moreover, we consider five potential suppliers for each item. The obtained values for TVP and TCP are 1,106,279.309 and 201,057.224; both are considered as the main determinative input parameters to the model.

\subsection{Supplier Ranking}

The main criteria to supply each item were extracted through interview with the Quality Assurance (QA) expert of the company to determine the importance degree of each criterion and the performance of each potential supplier in relation to each criterion. His opinion was collected in linguistic terms, and then was converted into triangular fuzzy numbers (see Table 2). The hierarchy of the supplier selection is represented in Figure 2. Furthermore, the final ranking of the suppliers is given in Table 4.

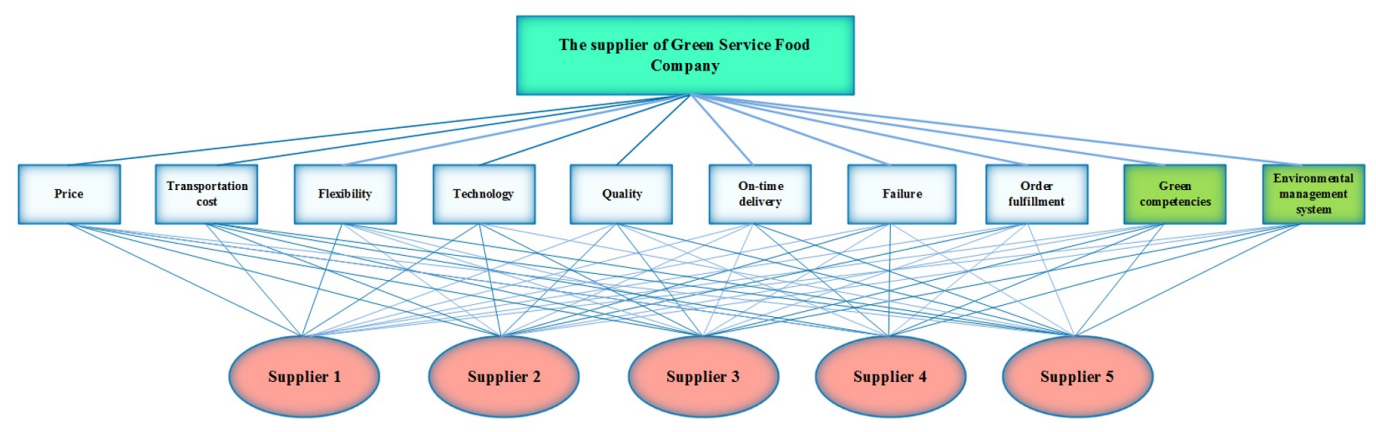

Figure 2. AHP hierarchy for supplier selection in Green Service Food Company. 
Table 4. Prioritization of suppliers.

\begin{tabular}{ccccccc}
\hline $\begin{array}{c}\text { Raw Food } \\
\text { Material }\end{array}$ & Supplier Ranking & \multicolumn{5}{c}{ Overall Weight of Suppliers } \\
\hline Meat & $S_{1}>S_{2}>S_{5}>S_{3}>S_{4}$ & 0.55 & 0.42 & 0.44 & 0.56 & 0.58 \\
Chicken & $S_{3}>S_{4}>S_{5}>S_{1}>S_{2}$ & 0.52 & 0.52 & 0.51 & 0.45 & 0.45 \\
Schnitzel & $S_{2}>S_{3}>S_{1}>S_{5}>S_{4}$ & 0.47 & 0.44 & 0.51 & 0.53 & 0.50 \\
Rice & $S_{2}>S_{1}>S_{3}>S_{4}>S_{5}$ & 0.36 & 0.39 & 0.45 & 0.47 & 0.45 \\
Fish & $S_{5}>S_{4}>S_{2}>S_{3}>S_{1}$ & 0.58 & 0.51 & 0.45 & 0.47 & 0.44 \\
Tomato paste & $S_{1}>S_{4}>S_{5}>S_{3}>S_{2}$ & 0.46 & 0.48 & 0.45 & 0.45 & 0.48 \\
Lemon juice & $S_{4}>S_{1}>S_{3}>S_{2}>S_{5}$ & 0.46 & 0.61 & 0.56 & 0.50 & 0.59 \\
Tomato & $S_{3}>S_{4}>S_{2}>S_{1}>S_{5}$ & 0.36 & 0.49 & 0.55 & 0.47 & 0.43 \\
Yogurt & $S_{5}>S_{2}>S_{3}>S_{1}>S_{4}$ & 0.50 & 0.48 & 0.52 & 0.52 & 0.48 \\
\hline
\end{tabular}

The details of the supplier ranking calculations are provided in Appendix A.

\subsection{Model Results}

After prioritizing the suppliers and calculating the importance of each supplier $\left(W_{r}\right)$, the proposed mathematical model has been solved using the CPLEX solver of GAMS software. This model determines the optimum allocation order of each item and finds out the best solution for the allocation order problem. It should be noted that the uncertainty level $(\psi)$ is determined by the market expert to be 0.1 , and the conservatism levels $\left(\Gamma_{r}^{1}\right.$ and $\left.\Gamma_{r}^{2}\right)$ are considered to be 0.5 for each item.

The advantages of the 1st objective $\left(W_{1}^{\prime}\right)$ and the 2nd objective $\left(W_{2}^{\prime}\right)$ are determined using the entropy approach proposed by Shannon [50]. Shannon entropy is only a particular, limit case of Renyi entropy [51] and has important applications regarding hierarchical tree structures [52]. It is an appropriate scale to be implemented on different cases of assessment in various decision-making processes [53]. Moreover, it can be employed to calculate the quantity of useful information presented by data itself. We take into account three combinations based on the market, production and QA experts as alternatives. The values of the 1st and 2 nd objectives are considered as two evaluation criteria, thus the decision-making matrix is defined in Table 5.

Table 5. Decision-making matrix in Shannon entropy.

\begin{tabular}{cccc}
\hline Experts & $\left(\boldsymbol{W}_{\mathbf{1}}^{\prime}, \boldsymbol{W}_{\mathbf{2}}^{\prime}\right)$ & 1st Objective & 2nd Objective \\
\hline Market & $(0.8,0.2)$ & $1,469,838.68$ & $135,018.95$ \\
Production & $(0.7,0.3)$ & $1,474,004.81$ & $135,950.58$ \\
QA & $(0.6,0.4)$ & $1,481,940.85$ & $136,858.73$ \\
\hline
\end{tabular}

Now we need to normalize the above $3 \times 2$ matrix, the result is shown in Table 6 .

Table 6. Normalized decision-making matrix in Shannon entropy.

\begin{tabular}{ccc}
\hline$\left(\boldsymbol{W}_{\mathbf{1}}^{\prime}, \boldsymbol{W}_{\mathbf{2}}^{\prime}\right)$ & 1st Objective & 2nd Objective \\
\hline$(0.8,0.2)$ & 0.332108 & 0.331068 \\
$(0.7,0.3)$ & 0.333049 & 0.333353 \\
$(0.6,0.4)$ & 0.334843 & 0.335579 \\
\hline
\end{tabular}

In the following, the entropy of each criterion $\left(E_{j}\right)$ should be calculated according to Equation (26).

$$
\begin{gathered}
E_{j}=-k \sum_{i=1}^{3} p_{i j} \cdot \ln p_{i j}, \quad \forall j \in 1,2, \\
k=\frac{1}{\ln 3}=0.910
\end{gathered}
$$


where $i$ and $j$ denote the criterion and alternative indexes, $k$ is a fixed value and $p_{i j}$ represents the values in the normalized matrix (cf. Table 6). Now, the deviation degree of criteria $\left(\operatorname{dev}_{j}\right)$ is calculated:

$$
\operatorname{dev}_{j}=1-E_{j}, \forall j \in\{1,2\} .
$$

In the final step, the assigned weight to each criterion $\left(w g_{j}\right)$ is obtained:

$$
\begin{gathered}
w g_{j}=\frac{d e v_{j}}{D E V}, \forall j \in\{1,2\}, \\
D E V=\sum_{j=1}^{2} d e v_{j} .
\end{gathered}
$$

The obtained values for $E_{j}, d e v_{j}$ and $w g_{j}$ are given in Table 7.

Table 7. Obtained results for the the assigned weight to each criterion.

\begin{tabular}{ccc}
\hline Variables & $\mathbf{j}=\mathbf{1}$ & $\mathbf{j}=\mathbf{2}$ \\
\hline$E_{j}$ & 0.999732 & 0.999723 \\
$d e v_{j}$ & 0.000268 & 0.000277 \\
$w g_{j}$ & 0.491743 & 0.508257 \\
\hline
\end{tabular}

Now, we should choose the best alternative considering the assigned weights of criteria. Since the 1st criterion (1st objective function) is a negative criterion (the lower value it has, the more desirable it is) and the 2 nd criterion (2nd objective function) is a positive criterion (the larger the value, the more desirable), the following equation is defined to determine the score of each alternative:

$$
\text { Score }_{i}=w g_{2} \times p_{i 2}-w g_{1} \times p_{i 1}, \quad \forall i \in\{1,2,3\}
$$

Table 8 presents the score of each alternative. As can be seen, the 3 rd alternative is chosen.

Table 8. Score of each alternative.

\begin{tabular}{ccc}
\hline Alternative & $\left(\boldsymbol{W}_{1}^{\prime}, \boldsymbol{W}_{2}^{\prime}\right)$ & Score \\
\hline 1 & $(0.8,0.2)$ & 0.004956 \\
2 & $(0.7,0.3)$ & 0.005654 \\
3 & $(0.6,0.4)$ & 0.005904 \\
\hline
\end{tabular}

By implementing the mathematical model, the allocation values have been determined; they represent the demand and the purchasing quantity of each item. Furthermore, the purchasing quantity of each item and the quantity of not fulfilled items are reported in Table 9. 
Table 9. Order quantity and fulfilled order of each item.

\begin{tabular}{cccc}
\hline $\begin{array}{c}\text { Raw Food } \\
\text { Material }\end{array}$ & Demand & $\begin{array}{c}\text { The Purchasing Quantity } \\
\text { of Item } \boldsymbol{r}\end{array}$ & $\begin{array}{c}\text { The Quantity of Item } \boldsymbol{r} \\
\text { Not Fulfilled }\end{array}$ \\
\hline Meat & 16,789 & 16,594 & 195 \\
Chicken & 102,640 & 102,640 & 0 \\
Schnitzel & 49,236 & 49,236 & 0 \\
Rice & 165,899 & 165,899 & 0 \\
Fish & 7801 & 7749 & 52 \\
Tomato paste & 8875 & 8875 & 0 \\
Lemon juice & 1136 & 1136 & 0 \\
Tomato & 22,471 & 22,471 & 0 \\
Yogurt & 386,005 & 386,005 & 0 \\
\hline
\end{tabular}

The obtained values for the RGP, 1st and 2nd objective functions with deviations values are shown in Table 10.

Table 10. Output results.

\begin{tabular}{cc}
\hline Variables & Value \\
\hline$d l_{1}^{+}$ & 375,661 \\
$d l_{1}^{-}$ & 0 \\
$d l_{2}^{+}$ & 0 \\
$d l_{2}^{-}$ & 64,198 \\
RGP objective & 0.331 \\
Total cost (1st objective) & $1,481,940$ \\
Total weighted purchase (2nd objective) & 136,858 \\
\hline
\end{tabular}

In the following, a sensitivity analysis is conducted on the uncertainty levels of $0,0.05,0.1,0.15$ and 0.2 to study the instability of the uncertainty and address specificity and accuracy [54,55]. It should be noted that the uncertainty level of 0 leads to a certain (deterministic) model that is not robust anymore. Under these different conditions, the obtained results are compared with each other, which would help managers to find the optimal policy at each level of uncertainty. To this end, the obtained values for the 1st and 2nd objective functions are illustrated in Figures 3 and 4 . Note that the trade-off between objectives is dependent on the purchasing quantity. It is expected that, with the increase in purchasing quantity, the 1st and 2nd objectives also increase. However, a larger uncertainty level may violate this trade-off. This would result in more shortage and, consequently, higher penalty costs, which increase the 1st objective and decrease the 2nd objective.

According to Figures 3 and 4, the obtained results for $\psi=0$ show the status of the problem in a certain condition, which has the best values for both objectives. Under uncertain conditions, which range from $\psi=0.05$ to $\psi=0.2$, the status is becoming worse and worse. These deviations from the best values are the imposed costs to remain feasible in different uncertain conditions. As is obvious, the maximum value of the 1st objective and the minimum value for the 2 nd objective are obtained for $\psi=0.2$. Therefore, managers should pay more attention, consider more resource and have a secondary plan in order to overcome these increases in total cost and shortages in fulfilling the required demands. These efforts may be made after analyzing and evaluating the behavior of the objectives under different conditions. 


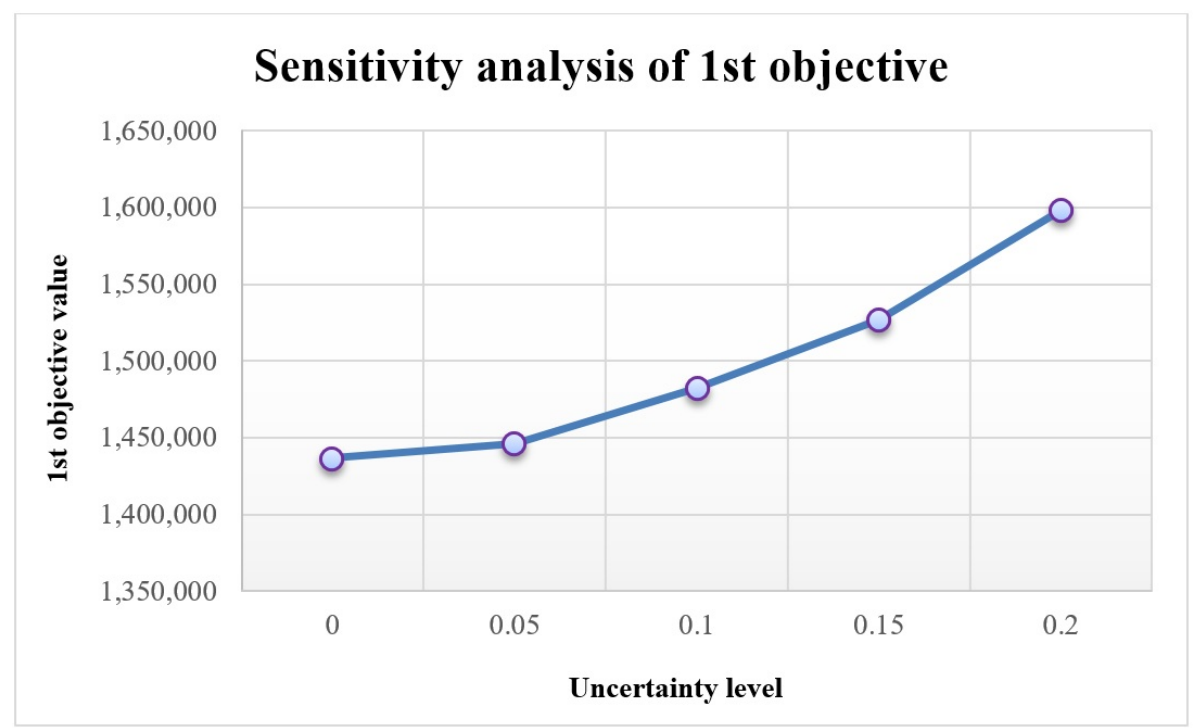

Figure 3. Sensitivity analysis of the 1st objective on different uncertainty levels.

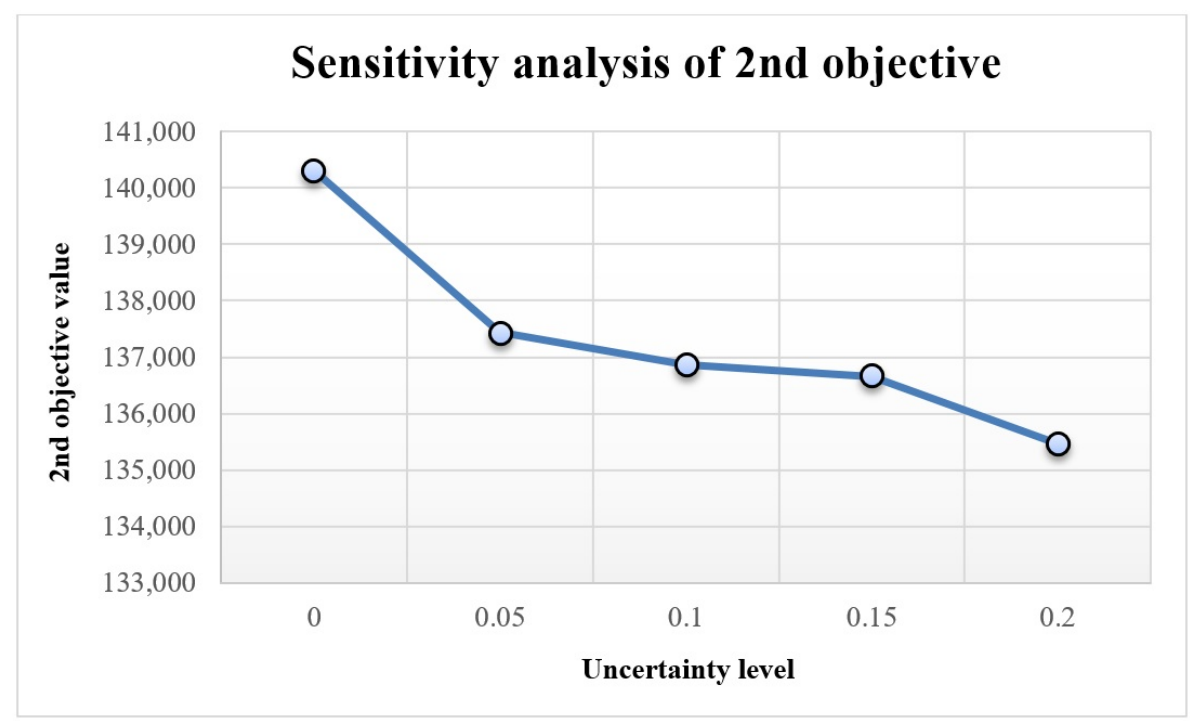

Figure 4. Sensitivity analysis of the 2nd objective on different uncertainty levels.

\subsection{Robustness Acceptance Threshold}

One of the most effective factors in robust decision-making is to determine to what extent it is valuable to make the problem robust. The main factor is to consider the budget constraint of the organization so that the budget value would specify how much the robustness is possible and valuable or not. To this end, according to the market expert's opinion, we consider a fixed uncertainty level of 0.1 and analyze the problem for different values of conservatism levels to find the threshold of robustness worthiness (TRW). Moreover, the budget limitation of USD 1,600,000 is applied to the proposed robust model. Table 11 shows the total cost against different combinations of conservatism levels, and Figure 5 highlights the threshold. 
Table 11. Obtained results for determining TRW.

\begin{tabular}{cccc}
\hline No. & $\boldsymbol{\Gamma}_{\boldsymbol{r}}^{\mathbf{1}}$ & $\boldsymbol{\Gamma}_{\boldsymbol{r}}^{\mathbf{1}}$ & Total Cost (USD) \\
\hline 1 & 0 & 0 & $1,224,789.891$ \\
2 & 0.1 & 0.1 & $1,293,525.1$ \\
3 & 0.2 & 0.2 & $1,353,025.573$ \\
4 & 0.25 & 0.25 & $1,370,919.078$ \\
5 & 0.3 & 0.3 & $1,419,997.981$ \\
6 & 0.35 & 0.35 & $1,424,101.349$ \\
7 & 0.4 & 0.4 & $1,451,492.486$ \\
8 & 0.45 & 0.45 & $1,472,103.694$ \\
9 & 0.5 & 0.5 & $1,481,940.852$ \\
10 & 0.55 & 0.55 & $1,499,531.49$ \\
11 & 0.6 & 0.6 & $1,529,625.198$ \\
12 & 0.65 & 0.65 & $1,546,078.626$ \\
13 & 0.7 & 0.7 & $1,565,525.203$ \\
14 & 0.75 & 0.75 & $1,589,070.859$ \\
15 & 0.76 & 0.76 & $1,589,413.319$ \\
16 & 0.77 & 0.77 & $1,593,410.867$ \\
17 & 0.78 & 0.78 & $1,597,219.738$ \\
$\mathbf{1 8}$ & $\mathbf{0 . 7 8 5}$ & $\mathbf{0 . 7 8 5}$ & $\mathbf{1 , 6 0 0 , 2 9 5 . 2 6 6}$ \\
19 & 0.8 & 0.8 & $1,664,102.453$ \\
20 & 1 & 1 & $1,755,981.394$ \\
\hline
\end{tabular}

As is clear from Table 11 and Figure 5, the approximate value of 0.785 is the recommended threshold value for both conservatism levels. The budget limitation would be violated for a greater value than 0.785 , and the robustness becomes unworthy due to problem's infeasibility.

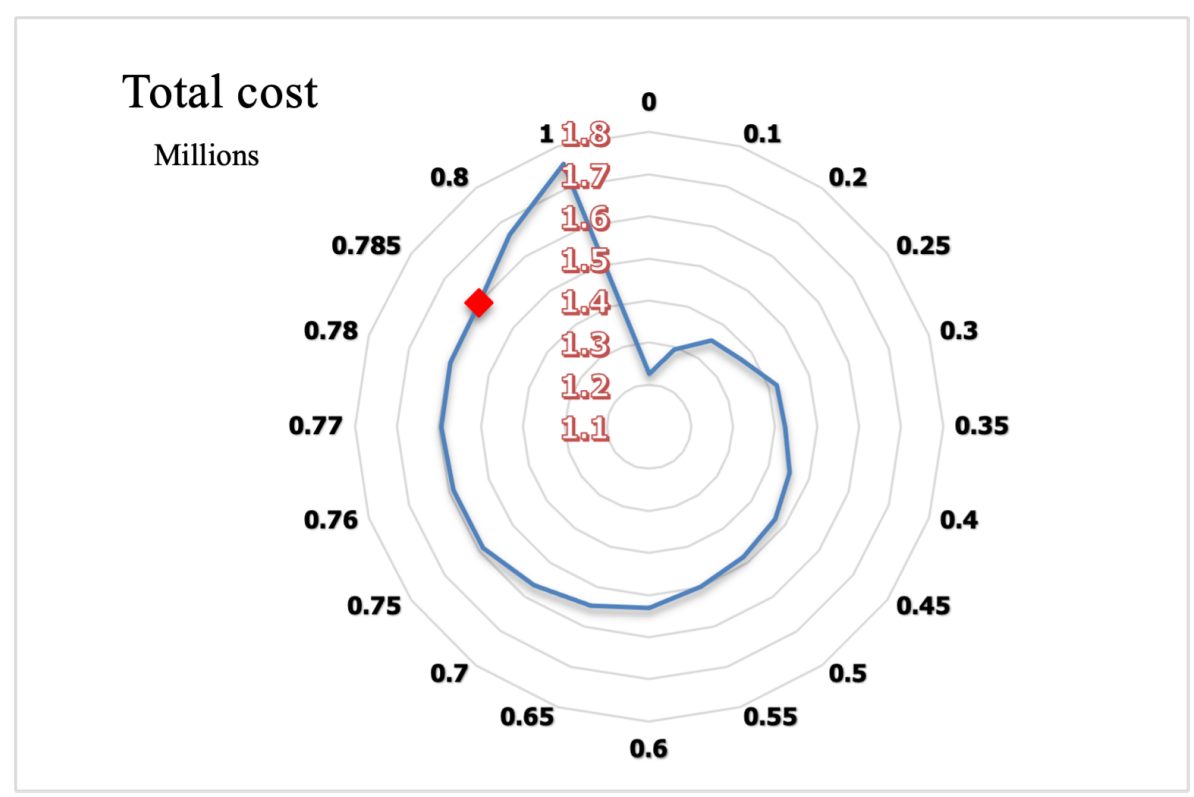

Figure 5. Analysis of the TRW.

\section{Discussion}

The numerical results provided an optimal plan to the management of Green Service Food Company under uncertain demands. First, the priority of the potential suppliers for each raw food material was determined to identify the superior suppliers. Based on real data, the optimization process was then performed to determine the total cost considering the maximization of the total purchasing value. Accordingly, the optimal supply plan was found including the purchasing quantity of each item from the best possible suppliers. This plan can be regarded as an efficient tool to conduct each supply for raw food materials. 
To study the instability of the real world and robustness of the solutions, a sensitivity analysis was performed on the parameter of uncertainty level. It was demonstrated that the total cost increases by $7.85 \%$ for an increase of $20 \%$ in the uncertainty level. Moreover, the total purchasing value increases by $2.51 \%$ for a decrease of $20 \%$ in the uncertainty level. On the other hand, an analytical experiment was designed to study the robustness acceptance threshold as an applicable option under uncertain conditions. To this end, a budget limitation was first proposed by the management, and then different tests were performed for different values of conservatism levels (budgets of uncertainty). It was revealed that the 18th breakpoint $\left(\Gamma_{r}^{1}=\Gamma_{r}^{2}=0.785\right)$ exceeds the budget limitation of USD $1,600,000$. This point can be considered as the critical stage of robustness.

The main contributions of this study were to design a framework addressing the robustness, sustainability and applicability of the green supplier selection problem in an agri-food supply chain. To do so, an integrated methodology was designed based on the gaps in the literature to provide the required requirements. It can inferred that the results obtained by this research can be employed in the future as an applicable managerial tool in decision-making processes of the company under uncertainty.

\section{Conclusions and Future Research Directions}

SCM, which includes different tasks, is one of the most important competitive factors for modern companies. At the initial stages, the supplier selection process is a critical step, aiming at selecting the best supplier. In this study, a GSS problem was addressed in an area where there are several raw agri-food materials and suppliers under uncertain condition. The proposed method consists of a novel integration of AHP and fuzzy TOPSIS (AHP- fuzzy TOPSIS) and RGP approach. At the first stage, AHP was employed to identify the criteria weights; then, the fuzzy TOPSIS method was applied to identify the importance degree of each supplier for supplying each item at the second stage. At the third stage, the allocation quantity to each supplier was determined by solving the proposed RMILGP model executed by CPLEX solver and using Shannon entropy method to determine the weights of the objective functions. To validate the proposed methodology, it was implemented by the Green Service Food Company in Iran, and the optimal policy was found out. Practically, this method was developed as a hybrid method under economic and GSS criteria and addressed the allocation of the orders for a multi-resource supplier selection problem in a GSCM context. Finally, a sensitivity analysis was performed on different uncertainty levels to support the managers optimally elaborate on the behavior of the objectives and optimal policies. Moreover, an analysis of different values of the conservatism levels was conducted to investigate TRW considering the budget limitation of the company. Finally, our proposed methodology could provide a robust and sustainable solution to the problem through integrating MCDM and robust optimization. This can be also considered for different variants of the problem under different real-world conditions and it is expected that the same performance will be represented.

As a future suggestion, the proposed methodology is capable of being implemented as a practical framework in similar supply chains such as flower supply chains. To extend the current study based on the main limitations, other uncertainty study methods such as grey systems [56], fuzzy programming [57] and stochastic optimal control [58] can be employed and compared to the current robust optimization approach. Moreover, Paretobased solution methods, e.g., well-known multi-objective algorithms, may be implemented and compared to the proposed RGP. Considering a planning horizon and supply chain reliability maximization as a 3rd objective in the model would make it even closer to real-world status and impact. Eventually, studying the application of electric vehicles in agri-food freight transportation [7] and blockchain technology within the agri-food supply chain [59] can be worthy of investigation to meet the requirements of this era. 
Author Contributions: E.B.T.: conceptualization, methodology, project administration, writingoriginal draft; Z.D.: formal analysis, software; G.-W.W.: data curation, supervision, writing-review and editing; H.T.: investigation, visualization, validation; M.S.: writing—original draft, investigation; N.S.M.: writing - review and editing, validation. All authors have read and agreed to the published version of the manuscript.

Funding: The research has been partially supported by the Faculty of Informatics and Management UHK specific research project 2107, Integration of Departmental Research Activities and Students' Research Activities Support.

Institutional Review Board Statement: Not applicable.

Informed Consent Statement: Not applicable.

Acknowledgments: The author would like to thank students Nosek K. and Novak J. for their cooperation on the topic.

Conflicts of Interest: The authors declare no conflict of interest.

\section{Abbreviations}

The following abbreviations are used in this manuscript:

The Sets, Indices and Parameters

$r=1,2, \cdots, R \quad$ Index of items;

$s=1,2, \cdots, S \quad$ Index of suppliers;

$P_{r s} \quad$ Purchasing cost of item $r$ from supplier $s$;

$O_{r s} \quad$ Order cost of item $i$ from supplier $s$;

$t_{i} \quad$ Transportation cost of item $i$;

$d_{s} \quad$ Distance from the supplier $s$;

$H_{r} \quad$ Holding cost of item $r$;

$W_{r s} \quad$ Overall weight (priority value) of the supplier $s$ to supply item $r$

(obtained by AHP-fuzzy TOPSIS method);

$q_{r s} \quad$ Average defect rate of item $r$ from supplier $s$;

$Q_{r} \quad$ Maximum acceptable defect rate of item $r$;

$D_{r} \quad$ Uncertain demand of item $r$;

$\bar{D}_{r} \quad$ Average demand of item $r$ at each period;

$\widehat{D}_{r} \quad$ Deviation quantity in the demand of item $r$;

$c_{r s} \quad$ Maximum acceptable capacity of supplier $s$ for item $r$

$c_{r s}^{\prime} \quad$ Minimum acceptable capacity of supplier $s$ for item $r$;

$\psi \quad$ Uncertainty level;

$\Gamma^{1}$ and $\Gamma^{2} \quad$ Conservatism levels of constraints from Equations (12) and (13), respectively;

$\alpha_{r} \quad$ Transformation coefficient of weight supplier $s$ to cost;

$B_{r} \quad$ Penalty cost for a unit shortage of item $r$;

$W_{1}^{\prime} \quad$ Advantage of the 1st objective based on the decision-maker idea;

$W_{2}^{\prime} \quad$ Advantage of the 2nd objective based on the decision-maker idea;

TCP Ideal value of the 1st objective;

TVP Ideal value of the 2nd objective.

Variables

$x_{r s} \quad$ Purchasing quantity of item $r$ from supplier $s$;

$y_{r s} \quad$ Binary variable; if the item $r$ is supplied from supplier $s$ is 1, otherwise 0;

$l_{r} \quad$ Shortage quantity of item $r$;

$d l_{1}^{+} \quad$ Positive deviation from the ideal value of 1st objective;

$d l_{1}^{-} \quad$ Negative deviation from the ideal value of 1st objective;

$d l_{2}^{+} \quad$ Positive deviation from the ideal value of 2 nd objective;

$d l_{2}^{-} \quad$ Negative deviation from the ideal value of 2 nd objective.

\section{Appendix A. The Calculations Related to AHP-Fuzzy TOPSIS}

This section provides the calculations related to the proposed AHP-fuzzy TOPSIS step by step. First, different criteria are numbered and then the decision matrix for each item is constructed. 
Table A1. Criteria numbering.

\begin{tabular}{cc}
\hline Criteria & No. \\
\hline Price & 1 \\
Transportation cost & 2 \\
Flexibility & 3 \\
Technology & 4 \\
Quality & 5 \\
On-time delivery & 6 \\
Failure & 7 \\
Order fulfilment & 8 \\
Green competencies & 9 \\
Environmental management system & 10 \\
\hline
\end{tabular}

Appendix A.1. Meat

Table A2. Pairwise comparisons matrix of meat.

\begin{tabular}{ccccccccccc}
\hline Meat & $\mathbf{1}$ & $\mathbf{2}$ & $\mathbf{3}$ & $\mathbf{4}$ & $\mathbf{5}$ & $\mathbf{6}$ & $\mathbf{7}$ & $\mathbf{8}$ & $\mathbf{9}$ & $\mathbf{1 0}$ \\
\hline 1 & 1 & 5 & 3 & 7 & 1 & 3 & 5 & 3 & 3 & 3 \\
2 & $1 / 5$ & 1 & 5 & 3 & $1 / 5$ & 3 & 1 & 1 & 3 & 3 \\
3 & $1 / 3$ & $1 / 5$ & 1 & 1 & $1 / 7$ & $1 / 3$ & $1 / 5$ & 1 & $1 / 3$ & $1 / 3$ \\
4 & $1 / 7$ & $1 / 3$ & 1 & 1 & $1 / 9$ & 1 & $1 / 3$ & $1 / 5$ & 1 & 1 \\
5 & 1 & 5 & 7 & 9 & 1 & 5 & 3 & 7 & 1 & 3 \\
6 & $1 / 3$ & $1 / 3$ & 3 & 1 & $1 / 5$ & 1 & 5 & 7 & 3 & 1 \\
7 & $1 / 5$ & 1 & 5 & 3 & $1 / 3$ & $1 / 5$ & 1 & 1 & 1 & 1 \\
8 & $1 / 3$ & 1 & 1 & 5 & $1 / 7$ & $1 / 7$ & 1 & 1 & 1 & 1 \\
9 & $1 / 3$ & $1 / 3$ & 3 & 1 & 1 & $1 / 3$ & 1 & 1 & 1 & 3 \\
10 & $1 / 3$ & $1 / 3$ & 3 & 1 & $1 / 3$ & 1 & 1 & 1 & $1 / 3$ & 1 \\
\hline
\end{tabular}

Table A3. Normalization matrix of meat.

\begin{tabular}{ccccccccccc}
\hline Meat & $\mathbf{1}$ & $\mathbf{2}$ & $\mathbf{3}$ & $\mathbf{4}$ & $\mathbf{5}$ & $\mathbf{6}$ & $\mathbf{7}$ & $\mathbf{8}$ & $\mathbf{9}$ & $\mathbf{1 0}$ \\
\hline 1 & 0.238 & 0.344 & 0.094 & 0.219 & 0.224 & 0.2 & 0.27 & 0.129 & 0.205 & 0.173 \\
2 & 0.048 & 0.069 & 0.156 & 0.094 & 0.045 & 0.2 & 0.054 & 0.043 & 0.205 & 0.173 \\
3 & 0.079 & 0.014 & 0.031 & 0.031 & 0.032 & 0.022 & 0.011 & 0.043 & 0.023 & 0.019 \\
4 & 0.034 & 0.023 & 0.031 & 0.031 & 0.025 & 0.067 & 0.018 & 0.009 & 0.068 & 0.058 \\
5 & 0.238 & 0.344 & 0.219 & 0.281 & 0.224 & 0.333 & 0.162 & 0.302 & 0.068 & 0.173 \\
6 & 0.079 & 0.023 & 0.094 & 0.031 & 0.045 & 0.067 & 0.27 & 0.302 & 0.205 & 0.058 \\
7 & 0.048 & 0.069 & 0.156 & 0.094 & 0.075 & 0.013 & 0.054 & 0.043 & 0.068 & 0.058 \\
8 & 0.079 & 0.069 & 0.031 & 0.156 & 0.032 & 0.01 & 0.054 & 0.043 & 0.068 & 0.058 \\
9 & 0.079 & 0.023 & 0.094 & 0.031 & 0.224 & 0.022 & 0.054 & 0.043 & 0.068 & 0.173 \\
10 & 0.079 & 0.023 & 0.094 & 0.031 & 0.075 & 0.067 & 0.054 & 0.043 & 0.023 & 0.058 \\
\hline
\end{tabular}

Table A4. Weight of each criterion for meat.

\begin{tabular}{ccccccccccc}
\hline Meat & $\mathbf{1}$ & $\mathbf{2}$ & $\mathbf{3}$ & $\mathbf{4}$ & $\mathbf{5}$ & $\mathbf{6}$ & $\mathbf{7}$ & $\mathbf{8}$ & $\mathbf{9}$ & $\mathbf{1 0}$ \\
\hline Weight & 0.209 & 0.109 & 0.031 & 0.036 & 0.234 & 0.117 & 0.068 & 0.060 & 0.081 & 0.055 \\
\hline
\end{tabular}

Now, the decision matrix for meat is as follows: 
Table A5. Decision matrix considering suppliers and similarity index for meat.

\begin{tabular}{|c|c|c|c|c|c|c|}
\hline \multirow{2}{*}{\multicolumn{2}{|c|}{ Suppliers }} & \multicolumn{5}{|c|}{ Meat } \\
\hline & & S1 & S2 & S3 & S4 & S5 \\
\hline \multirow{10}{*}{ Criteria } & 1 & $(1,3,5)$ & $(3,5,7)$ & $(5,7,9)$ & $(7,9,10)$ & $(9,10,10)$ \\
\hline & 2 & $(1,3,5)$ & $(3,5,7)$ & $(5,7,9)$ & $(7,9,10)$ & $(9,10,10)$ \\
\hline & 3 & $(1,3,5)$ & $(1,3,5)$ & $(9,10,10)$ & $(5,7,9)$ & $(0,0,1)$ \\
\hline & 4 & $(3,5,7)$ & $(1,3,5)$ & $(9,10,10)$ & $(5,7,9)$ & $(5,7,9)$ \\
\hline & 5 & $(5,7,9)$ & $(1,3,5)$ & $(3,5,7)$ & $(7,9,10)$ & $(1,3,5)$ \\
\hline & 6 & $(1,3,5)$ & $(1,3,5)$ & $(9,10,10)$ & $(7,9,10)$ & $(1,3,5)$ \\
\hline & 7 & $(7,9,10)$ & $(5,7,9)$ & $(5,7,9)$ & $(9,10,10)$ & $(3,5,7)$ \\
\hline & 8 & $(1,3,5)$ & $(9,10,10)$ & $(5,7,9)$ & $(7,9,10)$ & $(7,9,10)$ \\
\hline & 9 & $(1,3,5)$ & $(5,7,9)$ & $(5,7,9)$ & $(1,3,5)$ & $(7,9,10)$ \\
\hline & 10 & $(9,10,10)$ & $(1,3,5)$ & $(9,10,10)$ & $(3,5,7)$ & $(5,7,9)$ \\
\hline \multirow{3}{*}{ Variables } & $S_{i}^{+}$ & 0.49 & 0.2141 & 0.3176 & 0.5091 & 0.2599 \\
\hline & $S_{i}^{-}$ & 0.6858 & 0.2741 & 0.2466 & 0.3673 & 0.3163 \\
\hline & $\stackrel{\iota}{C}_{i}$ & 0.5832 & 0.5614 & 0.4371 & 0.4191 & 0.549 \\
\hline
\end{tabular}

Appendix A.2. Chicken

Table A6. Pairwise comparisons matrix of chicken.

\begin{tabular}{ccccccccccc}
\hline Chicken & $\mathbf{1}$ & $\mathbf{2}$ & $\mathbf{3}$ & $\mathbf{4}$ & $\mathbf{5}$ & $\mathbf{6}$ & $\mathbf{7}$ & $\mathbf{8}$ & $\mathbf{9}$ & $\mathbf{1 0}$ \\
\hline 1 & 1 & 5 & $1 / 9$ & $1 / 9$ & 9 & 5 & 9 & 9 & 3 & 7 \\
2 & $1 / 5$ & 1 & 1 & $1 / 9$ & 3 & $1 / 3$ & 7 & $1 / 7$ & $1 / 3$ & 5 \\
3 & 9 & 1 & 1 & $1 / 5$ & 9 & 3 & $1 / 5$ & 5 & 1 & 1 \\
4 & 9 & 9 & 5 & 1 & 9 & 7 & 3 & 1 & 7 & $1 / 9$ \\
5 & $1 / 9$ & $1 / 3$ & $1 / 9$ & $1 / 9$ & 1 & 7 & 5 & 3 & 9 & $1 / 3$ \\
6 & $1 / 5$ & 3 & $1 / 3$ & $1 / 7$ & $1 / 7$ & 1 & 5 & 5 & $1 / 9$ & 3 \\
7 & $1 / 9$ & $1 / 7$ & 5 & $1 / 3$ & $1 / 5$ & $1 / 5$ & 1 & 5 & 1 & 9 \\
8 & $1 / 9$ & 7 & $1 / 5$ & 1 & $1 / 3$ & $1 / 5$ & $1 / 5$ & 1 & $1 / 5$ & 3 \\
9 & $1 / 3$ & 3 & 1 & $1 / 7$ & $1 / 9$ & 9 & 1 & 5 & 1 & 3 \\
10 & $1 / 7$ & $1 / 5$ & 1 & 9 & 3 & $1 / 3$ & $1 / 9$ & $1 / 3$ & $1 / 3$ & 1 \\
\hline
\end{tabular}

Table A7. Normalization matrix of chicken.

\begin{tabular}{ccccccccccc}
\hline Chicken & $\mathbf{1}$ & $\mathbf{2}$ & $\mathbf{3}$ & $\mathbf{4}$ & $\mathbf{5}$ & $\mathbf{6}$ & $\mathbf{7}$ & $\mathbf{8}$ & $\mathbf{9}$ & $\mathbf{1 0}$ \\
\hline 1 & 0.049 & 0.168 & 0.008 & 0.009 & 0.259 & 0.151 & 0.286 & 0.261 & 0.131 & 0.216 \\
2 & 0.01 & 0.034 & 0.068 & 0.009 & 0.086 & 0.01 & 0.222 & 0.004 & 0.015 & 0.154 \\
3 & 0.445 & 0.034 & 0.068 & 0.016 & 0.259 & 0.091 & 0.006 & 0.145 & 0.044 & 0.031 \\
4 & 0.445 & 0.303 & 0.339 & 0.082 & 0.259 & 0.212 & 0.095 & 0.029 & 0.305 & 0.003 \\
5 & 0.005 & 0.011 & 0.008 & 0.009 & 0.029 & 0.212 & 0.159 & 0.087 & 0.392 & 0.01 \\
6 & 0.01 & 0.101 & 0.023 & 0.012 & 0.004 & 0.03 & 0.159 & 0.145 & 0.005 & 0.092 \\
7 & 0.005 & 0.005 & 0.339 & 0.027 & 0.006 & 0.006 & 0.032 & 0.145 & 0.044 & 0.277 \\
8 & 0.005 & 0.236 & 0.014 & 0.082 & 0.01 & 0.006 & 0.006 & 0.029 & 0.009 & 0.092 \\
9 & 0.016 & 0.101 & 0.068 & 0.012 & 0.003 & 0.272 & 0.032 & 0.145 & 0.044 & 0.092 \\
10 & 0.007 & 0.007 & 0.068 & 0.741 & 0.086 & 0.01 & 0.004 & 0.01 & 0.015 & 0.031 \\
\hline
\end{tabular}

Table A8. Weight of each criterion for chicken.

\begin{tabular}{ccccccccccc}
\hline Meat & $\mathbf{1}$ & $\mathbf{2}$ & $\mathbf{3}$ & $\mathbf{4}$ & $\mathbf{5}$ & $\mathbf{6}$ & $\mathbf{7}$ & $\mathbf{8}$ & $\mathbf{9}$ & $\mathbf{1 0}$ \\
\hline Weight & 0.154 & 0.061 & 0.114 & 0.207 & 0.092 & 0.058 & 0.089 & 0.049 & 0.079 & 0.098 \\
\hline
\end{tabular}

Now, the decision matrix for chicken is as follows: 
Table A9. Decision matrix considering suppliers and similarity index for chicken.

\begin{tabular}{|c|c|c|c|c|c|c|}
\hline \multirow{2}{*}{\multicolumn{2}{|c|}{ Suppliers }} & \multicolumn{5}{|c|}{ Chicken } \\
\hline & & S1 & S2 & S3 & S4 & S5 \\
\hline \multirow{10}{*}{ Criteria } & 1 & $(9,10,10)$ & $(1,3,5)$ & $(5,7,9)$ & $(7,9,10)$ & $(9,10,10)$ \\
\hline & 2 & $(9,10,10)$ & $(9,10,10)$ & $(5,7,9)$ & $(5,7,9)$ & $(9,10,10)$ \\
\hline & 3 & $(1,3,5)$ & $(9,10,10)$ & $(5,7,9)$ & $(1,3,5)$ & $(7,9,10)$ \\
\hline & 4 & $(1,3,5)$ & $(1,3,5)$ & $(7,9,10)$ & $(3,5,7)$ & $(3,5,7)$ \\
\hline & 5 & $(5,7,9)$ & $(5,7,9)$ & $(3,5,7)$ & $(7,9,10)$ & $(1,3,5)$ \\
\hline & 6 & $(1,3,5)$ & $(1,3,5)$ & $(3,5,7)$ & $(7,9,10)$ & $(3,5,7)$ \\
\hline & 7 & $(7,9,10)$ & $(7,9,10)$ & $(9,10,10)$ & $(9,10,10)$ & $(3,5,7)$ \\
\hline & 8 & $(3,5,7)$ & $(5,7,9)$ & $(3,5,7)$ & $(9,10,10)$ & $(9,10,10)$ \\
\hline & 9 & $(5,7,9)$ & $(3,5,7)$ & $(7,9,10)$ & $(3,5,7)$ & $(5,7,9)$ \\
\hline & 10 & $(3,5,7)$ & $(5,7,9)$ & $(9,10,10)$ & $(7,9,10)$ & $(9,10,10)$ \\
\hline \multirow{3}{*}{ Variables } & $S_{i}^{+}$ & 0.2909 & 0.459 & 0.6894 & 0.3704 & 0.4568 \\
\hline & $S_{i}^{-}$ & 0.2391 & 0.3722 & 0.7055 & 0.401 & 0.4896 \\
\hline & $\stackrel{l}{C}_{i}$ & 0.4511 & 0.4478 & 0.5058 & 0.5198 & 0.5174 \\
\hline
\end{tabular}

Appendix A.3. Schnitzel

Table A10. Pairwise comparisons matrix of schnitzel.

\begin{tabular}{ccccccccccc}
\hline Schnitzel & $\mathbf{1}$ & $\mathbf{2}$ & $\mathbf{3}$ & $\mathbf{4}$ & $\mathbf{5}$ & $\mathbf{6}$ & $\mathbf{7}$ & $\mathbf{8}$ & $\mathbf{9}$ & $\mathbf{1 0}$ \\
\hline 1 & 1 & 5 & 7 & 3 & 7 & $1 / 9$ & 3 & 7 & $1 / 7$ \\
2 & $1 / 5$ & 1 & 9 & 5 & 9 & 9 & $1 / 5$ & 5 & 3 \\
3 & $1 / 7$ & $1 / 9$ & 1 & 7 & 5 & 9 & 1 & 1 & 5 & 9 \\
4 & $1 / 3$ & $1 / 5$ & $1 / 7$ & 1 & 1 & 3 & 3 & $1 / 3$ & 1 & 5 \\
5 & $1 / 7$ & $1 / 9$ & $1 / 5$ & 1 & 1 & 1 & 1 & 7 & 1 & 3 \\
6 & 9 & $1 / 9$ & $1 / 9$ & $1 / 3$ & 1 & 1 & 5 & 1 & 9 & 9 \\
7 & $1 / 3$ & 5 & 1 & $1 / 3$ & 1 & $1 / 5$ & 1 & 1 & $1 / 5$ & $1 / 3$ \\
8 & $1 / 7$ & $1 / 5$ & 1 & 3 & $1 / 7$ & 1 & 1 & 1 & 3 \\
9 & 7 & $1 / 3$ & $1 / 5$ & 1 & 1 & $1 / 9$ & 5 & $1 / 3$ & 1 & 5 \\
10 & $1 / 9$ & 3 & $1 / 9$ & $1 / 5$ & $1 / 3$ & $1 / 9$ & 3 & $1 / 5$ & $1 / 5$ & 1 \\
\hline
\end{tabular}

Table A11. Normalization matrix of schnitzel.

\begin{tabular}{ccccccccccc}
\hline Schnitzel & $\mathbf{1}$ & $\mathbf{2}$ & $\mathbf{3}$ & $\mathbf{4}$ & $\mathbf{5}$ & $\mathbf{6}$ & $\mathbf{7}$ & $\mathbf{8}$ & $\mathbf{9}$ & $\mathbf{1 0}$ \\
\hline 1 & 0.054 & 0.332 & 0.354 & 0.137 & 0.264 & 0.005 & 0.129 & 0.293 & 0.006 & 0.193 \\
2 & 0.011 & 0.066 & 0.455 & 0.229 & 0.34 & 0.367 & 0.009 & 0.209 & 0.127 & 0.007 \\
3 & 0.008 & 0.007 & 0.051 & 0.32 & 0.189 & 0.367 & 0.043 & 0.042 & 0.212 & 0.193 \\
4 & 0.018 & 0.013 & 0.007 & 0.046 & 0.038 & 0.122 & 0.129 & 0.014 & 0.042 & 0.107 \\
5 & 0.008 & 0.007 & 0.01 & 0.046 & 0.038 & 0.041 & 0.043 & 0.293 & 0.042 & 0.064 \\
6 & 0.489 & 0.007 & 0.006 & 0.015 & 0.038 & 0.041 & 0.216 & 0.042 & 0.382 & 0.193 \\
7 & 0.018 & 0.332 & 0.051 & 0.015 & 0.038 & 0.008 & 0.043 & 0.042 & 0.008 & 0.007 \\
8 & 0.008 & 0.013 & 0.051 & 0.137 & 0.005 & 0.041 & 0.043 & 0.042 & 0.127 & 0.107 \\
9 & 0.38 & 0.022 & 0.01 & 0.046 & 0.038 & 0.005 & 0.216 & 0.014 & 0.042 & 0.107 \\
10 & 0.006 & 0.199 & 0.006 & 0.009 & 0.013 & 0.005 & 0.129 & 0.008 & 0.008 & 0.021 \\
\hline
\end{tabular}

Table A12. Weight of each criterion for schnitzel.

\begin{tabular}{ccccccccccc}
\hline Schnitzel & $\mathbf{1}$ & $\mathbf{2}$ & $\mathbf{3}$ & $\mathbf{4}$ & $\mathbf{5}$ & $\mathbf{6}$ & $\mathbf{7}$ & $\mathbf{8}$ & $\mathbf{9}$ & $\mathbf{1 0}$ \\
\hline Weight & 0.177 & 0.182 & 0.143 & 0.054 & 0.059 & 0.143 & 0.056 & 0.057 & 0.088 & 0.040 \\
\hline
\end{tabular}

Now, the decision matrix for schnitzel is as follows: 
Table A13. Decision matrix considering suppliers and similarity index for schnitzel.

\begin{tabular}{|c|c|c|c|c|c|c|}
\hline \multirow{2}{*}{\multicolumn{2}{|c|}{ Suppliers }} & \multicolumn{5}{|c|}{ Schnitzel } \\
\hline & & S1 & S2 & S3 & S4 & S5 \\
\hline \multirow{10}{*}{ Criteria } & 1 & $(5,7,9)$ & $(5,7,9)$ & $(7,9,10)$ & $(7,9,10)$ & $(7,9,10)$ \\
\hline & 2 & $(3,5,7)$ & $(7,9,10)$ & $(7,9,10)$ & $(1,3,5)$ & $(1,3,5)$ \\
\hline & 3 & $(5,7,9)$ & $(9,10,10)$ & $(3,5,7)$ & $(5,7,9)$ & $(3,5,7)$ \\
\hline & 4 & $(7,9,10)$ & $(3,5,7)$ & $(5,7,9)$ & $(7,9,10)$ & $(9,10,10)$ \\
\hline & 5 & $(9,10,10)$ & $(5,7,9)$ & $(1,3,5)$ & $(1,3,5)$ & $(3,5,7)$ \\
\hline & 6 & $(9,10,10)$ & $(3,5,7)$ & $(9,10,10)$ & $(3,5,7)$ & $(9,10,10)$ \\
\hline & 7 & $(3,5,7)$ & $(1,3,5)$ & $(3,5,7)$ & $(7,9,10)$ & $(5,7,9)$ \\
\hline & 8 & $(3,5,7)$ & $(9,10,10)$ & $(5,7,9)$ & $(5,7,9)$ & $(9,10,10)$ \\
\hline & 9 & $(3,5,7)$ & $(7,9,10)$ & $(7,9,10)$ & $(3,5,7)$ & $(5,7,9)$ \\
\hline & 10 & $(1,3,5)$ & $(1,3,5)$ & $(5,7,9)$ & $(7,9,10)$ & $(9,10,10)$ \\
\hline \multirow{3}{*}{ Variables } & $S_{i}^{+}$ & 0.4994 & 0.5016 & 0.4314 & 0.5985 & 0.5713 \\
\hline & $S_{i}^{-}$ & 0.5064 & 0.5598 & 0.4492 & 0.4794 & 0.4968 \\
\hline & $C_{i}$ & 0.5035 & 0.5274 & 0.5102 & 0.4448 & 0.4651 \\
\hline
\end{tabular}

Appendix A.4. Rice

Table A14. Pairwise comparisons matrix of rice.

\begin{tabular}{ccccccccccc}
\hline Rice & $\mathbf{1}$ & $\mathbf{2}$ & $\mathbf{3}$ & $\mathbf{4}$ & $\mathbf{5}$ & $\mathbf{6}$ & $\mathbf{7}$ & $\mathbf{8}$ & $\mathbf{9}$ & $\mathbf{1 0}$ \\
\hline 1 & 1 & 3 & $1 / 7$ & $1 / 5$ & 1 & 9 & 5 & 5 & 9 & $1 / 7$ \\
2 & $1 / 3$ & 1 & 5 & $1 / 9$ & 7 & 1 & 1 & 3 & $1 / 5$ & 3 \\
3 & 7 & $1 / 5$ & 1 & 7 & 7 & 5 & 5 & $1 / 7$ & 9 & 3 \\
4 & 5 & 9 & $1 / 7$ & 1 & $1 / 5$ & 3 & 9 & 1 & 3 & 5 \\
5 & 1 & $1 / 7$ & $1 / 7$ & 5 & 1 & 7 & 3 & $1 / 3$ & 7 & 5 \\
6 & $1 / 9$ & 1 & $1 / 5$ & $1 / 3$ & $1 / 7$ & 1 & $1 / 5$ & 7 & 5 & 7 \\
7 & $1 / 5$ & 1 & $1 / 5$ & $1 / 9$ & $1 / 3$ & 5 & 1 & 5 & 3 & 7 \\
8 & $1 / 5$ & $1 / 3$ & 7 & 1 & 3 & $1 / 7$ & $1 / 5$ & 1 & $1 / 9$ & $1 / 7$ \\
9 & $1 / 9$ & 5 & $1 / 9$ & $1 / 3$ & $1 / 7$ & $1 / 5$ & $1 / 3$ & 9 & 1 & 5 \\
10 & 7 & $1 / 3$ & $1 / 3$ & $1 / 5$ & $1 / 5$ & $1 / 7$ & $1 / 7$ & 7 & $1 / 5$ & 1 \\
\hline
\end{tabular}

Table A15. Normalization matrix of rice.

\begin{tabular}{ccccccccccc}
\hline Rice & $\mathbf{1}$ & $\mathbf{2}$ & $\mathbf{3}$ & $\mathbf{4}$ & $\mathbf{5}$ & $\mathbf{6}$ & $\mathbf{7}$ & $\mathbf{8}$ & $\mathbf{9}$ & $\mathbf{1 0}$ \\
\hline 1 & 0.046 & 0.143 & 0.01 & 0.013 & 0.05 & 0.286 & 0.201 & 0.13 & 0.24 & 0.004 \\
2 & 0.015 & 0.048 & 0.35 & 0.007 & 0.35 & 0.032 & 0.04 & 0.078 & 0.005 & 0.083 \\
3 & 0.319 & 0.01 & 0.07 & 0.458 & 0.35 & 0.159 & 0.201 & 0.004 & 0.24 & 0.083 \\
4 & 0.228 & 0.428 & 0.01 & 0.065 & 0.01 & 0.095 & 0.362 & 0.026 & 0.08 & 0.138 \\
5 & 0.046 & 0.007 & 0.01 & 0.327 & 0.05 & 0.222 & 0.121 & 0.009 & 0.187 & 0.138 \\
6 & 0.005 & 0.048 & 0.014 & 0.022 & 0.007 & 0.032 & 0.008 & 0.182 & 0.133 & 0.193 \\
7 & 0.009 & 0.048 & 0.014 & 0.007 & 0.017 & 0.159 & 0.04 & 0.13 & 0.08 & 0.193 \\
8 & 0.009 & 0.016 & 0.49 & 0.065 & 0.15 & 0.005 & 0.008 & 0.026 & 0.003 & 0.004 \\
9 & 0.005 & 0.238 & 0.008 & 0.022 & 0.007 & 0.006 & 0.013 & 0.234 & 0.027 & 0.138 \\
10 & 0.319 & 0.016 & 0.023 & 0.013 & 0.01 & 0.005 & 0.006 & 0.182 & 0.005 & 0.028 \\
\hline
\end{tabular}

Table A16. Weight of each criterion for rice.

\begin{tabular}{ccccccccccc}
\hline Rice & $\mathbf{1}$ & $\mathbf{2}$ & $\mathbf{3}$ & $\mathbf{4}$ & $\mathbf{5}$ & $\mathbf{6}$ & $\mathbf{7}$ & $\mathbf{8}$ & $\mathbf{9}$ & $\mathbf{1 0}$ \\
\hline Weight & 0.112 & 0.101 & 0.189 & 0.144 & 0.112 & 0.064 & 0.070 & 0.078 & 0.070 & 0.061 \\
\hline
\end{tabular}

Now, the decision matrix for rice is as follows: 
Table A17. Decision matrix considering suppliers and similarity index for rice.

\begin{tabular}{|c|c|c|c|c|c|c|}
\hline \multicolumn{2}{|c|}{ Suppliers } & \multicolumn{5}{|c|}{ Rice } \\
\hline & & S1 & $\mathrm{S} 2$ & S3 & $\mathrm{S} 4$ & S5 \\
\hline \multirow{10}{*}{ Criteria } & 1 & $(9,10,10)$ & $(7,9,10)$ & $(3,5,7)$ & $(5,7,9)$ & $(5,7,9)$ \\
\hline & 2 & $(1,3,5)$ & $(3,5,7)$ & $(1,3,5)$ & $(1,3,5)$ & $(3,5,7)$ \\
\hline & 3 & $(5,7,9)$ & $(1,3,5)$ & $(9,10,10)$ & $(9,10,10)$ & $(5,7,9)$ \\
\hline & 4 & $(5,7,9)$ & $(3,5,7)$ & $(9,10,10)$ & $(3,5,7)$ & $(1,3,5)$ \\
\hline & 5 & $(7,9,10)$ & $(3,5,7)$ & $(3,5,7)$ & $(5,7,9)$ & $(1,3,5)$ \\
\hline & 6 & $(1,3,5)$ & $(9,10,10)$ & $(9,10,10)$ & $(5,7,9)$ & $(1,3,5)$ \\
\hline & 7 & $(3,5,7)$ & $(3,5,7)($ & $9,10,10)$ & $(1,3,5)$ & $(1,3,5)$ \\
\hline & 8 & $(1,3,5)$ & $(7,9,10)$ & $(7,9,10)$ & $(7,9,10)$ & $(5,7,9)$ \\
\hline & 9 & $(5,7,9)$ & $(3,5,7)$ & $(7,9,10)$ & $(1,3,5)$ & $(7,9,10)$ \\
\hline & 10 & $(1,3,5)$ & $(3,5,7)$ & $(7,9,10)$ & $(7,9,10)$ & $(1,3,5)$ \\
\hline \multirow{3}{*}{ Variables } & $S_{i}^{+}$ & 0.5863 & 0.258 & 0.5455 & 0.5573 & 0.4213 \\
\hline & $S_{i}^{-}$ & 0.4798 & 0.2317 & 0.4459 & 0.3542 & 23.82 \\
\hline & $C_{i}$ & 0.45 & 0.4731 & 0.4497 & 0.3886 & 0.3612 \\
\hline
\end{tabular}

Appendix A.5. Fish

Table A18. Pairwise comparisons matrix of fish.

\begin{tabular}{ccccccccccc}
\hline Fish & $\mathbf{1}$ & $\mathbf{2}$ & $\mathbf{3}$ & $\mathbf{4}$ & $\mathbf{5}$ & $\mathbf{6}$ & $\mathbf{7}$ & $\mathbf{8}$ & $\mathbf{9}$ & $\mathbf{1 0}$ \\
\hline 1 & 1 & 9 & 3 & $1 / 5$ & $1 / 5$ & $1 / 5$ & 9 & $1 / 7$ & $1 / 7$ & 5 \\
2 & $1 / 9$ & 1 & 5 & 1 & $1 / 3$ & 5 & $1 / 7$ & 9 & 9 & 7 \\
3 & $1 / 3$ & $1 / 5$ & 1 & $1 / 7$ & $1 / 9$ & $1 / 9$ & 5 & 9 & $1 / 5$ & 7 \\
4 & 5 & 1 & 7 & 1 & 5 & 5 & 7 & 5 & 7 & $1 / 5$ \\
5 & 5 & 3 & 9 & $1 / 5$ & 1 & 9 & 7 & $1 / 5$ & 5 & 7 \\
6 & 5 & $1 / 5$ & 9 & $1 / 5$ & $1 / 9$ & 1 & 9 & $1 / 5$ & 3 & 7 \\
7 & $1 / 9$ & 7 & $1 / 5$ & $1 / 7$ & $1 / 7$ & $1 / 9$ & 1 & $1 / 3$ & $1 / 9$ & 7 \\
8 & 7 & $1 / 9$ & $1 / 9$ & $1 / 5$ & 5 & 5 & 3 & 1 & $1 / 9$ & 1 \\
9 & 7 & $1 / 9$ & 5 & $1 / 7$ & $1 / 5$ & $1 / 3$ & 9 & 9 & 1 & 7 \\
10 & $1 / 5$ & $1 / 7$ & $1 / 7$ & 5 & $1 / 7$ & $1 / 7$ & $1 / 7$ & 1 & $1 / 7$ & 1 \\
\hline
\end{tabular}

Table A19. Normalization matrix of fish.

\begin{tabular}{|c|c|c|c|c|c|c|c|c|c|c|}
\hline Fish & 1 & 2 & 3 & 4 & 5 & 6 & 7 & 8 & 9 & 10 \\
\hline 1 & 0.033 & 0.414 & 0.076 & 0.024 & 0.016 & 0.008 & 0.179 & 0.004 & 0.006 & 0.102 \\
\hline 2 & 0.004 & 0.046 & 0.127 & 0.122 & 0.027 & 0.193 & 0.003 & 0.258 & 0.35 & 0.142 \\
\hline 3 & 0.011 & 0.009 & 0.025 & 0.017 & 0.009 & 0.004 & 0.099 & 0.258 & 0.008 & 0.142 \\
\hline 4 & 0.163 & 0.046 & 0.177 & 0.122 & 0.408 & 0.193 & 0.139 & 0.143 & 0.272 & 0.004 \\
\hline 5 & 0.163 & 0.138 & 0.228 & 0.024 & 0.082 & 0.348 & 0.139 & 0.006 & 0.194 & 0.142 \\
\hline 6 & 0.163 & 0.009 & 0.228 & 0.024 & 0.009 & 0.039 & 0.179 & 0.006 & 0.117 & 0.142 \\
\hline 7 & 0.004 & 0.322 & 0.005 & 0.017 & 0.012 & 0.004 & 0.02 & 0.01 & 0.004 & 0.142 \\
\hline 8 & 0.228 & 0.005 & 0.003 & 0.024 & 0.408 & 0.193 & 0.06 & 0.029 & 0.004 & 0.02 \\
\hline 9 & 0.228 & 0.005 & 0.127 & 0.017 & 0.016 & 0.013 & 0.179 & 0.258 & 0.039 & 0.142 \\
\hline 10 & 0.007 & 0.007 & 0.004 & 0.608 & 0.012 & 0.006 & 0.003 & 0.029 & 0.006 & 0.02 \\
\hline
\end{tabular}

Table A20. Weight of each criterion for fish.

\begin{tabular}{ccccccccccc}
\hline Fish & $\mathbf{1}$ & $\mathbf{2}$ & $\mathbf{3}$ & $\mathbf{4}$ & $\mathbf{5}$ & $\mathbf{6}$ & $\mathbf{7}$ & $\mathbf{8}$ & $\mathbf{9}$ & $\mathbf{1 0}$ \\
\hline Weight & 0.086 & 0.127 & 0.058 & 0.167 & 0.146 & 0.092 & 0.054 & 0.097 & 0.102 & 0.070 \\
\hline
\end{tabular}

Now, the decision matrix for fish is as follows: 
Table A21. Decision matrix considering suppliers and similarity index for fish.

\begin{tabular}{|c|c|c|c|c|c|c|}
\hline \multicolumn{2}{|c|}{ Suppliers } & \multicolumn{5}{|c|}{ Fish } \\
\hline & & S1 & S2 & S3 & S4 & S5 \\
\hline \multirow{10}{*}{ Criteria } & 1 & $(1,3,5)$ & $(3,5,7)$ & $(3,5,7)$ & $(5,7,9)$ & $(5,7,9)$ \\
\hline & 2 & $(1,3,5)$ & $(3,5,7)$ & $(5,7,9)$ & $(1,3,5)$ & $(9,10,10)$ \\
\hline & 3 & $(7,9,10)$ & $(5,7,9)$ & $(5,7,9)$ & $(3,5,7)$ & $(5,7,9)$ \\
\hline & 4 & $(9,10,10)$ & $(5,7,9)$ & $(5,7,9)$ & $(3,5,7)$ & $(5,7,9)$ \\
\hline & 5 & $(7,9,10)$ & $(7,9,10)$ & $(3,5,7)$ & $(3,5,7)$ & $(9,10,10)$ \\
\hline & 6 & $(1,3,5)$ & $(9,10,10)$ & $(9,10,10)$ & $(7,9,10)$ & $(1,3,5)$ \\
\hline & 7 & $(3,5,7)$ & $(3,5,7)$ & $(7,9,10)$ & $(1,3,5)$ & $(7,9,10)$ \\
\hline & 8 & $(1,3,5)$ & $(7,9,10)$ & $(5,7,9)$ & $(7,9,10)$ & $(7,9,10)$ \\
\hline & 9 & $(9,10,10)$ & $(9,10,10)$ & $(3,5,7)$ & $(7,9,10)$ & $(1,3,5)$ \\
\hline & 10 & $(1,3,5)$ & $(7,9,10)$ & $(5,7,9)$ & $(5,7,9)$ & $(9,10,10)$ \\
\hline \multirow{3}{*}{ Variables } & $S_{i}^{+}$ & 0.6807 & 0.5467 & 0.4677 & 0.313 & 0.5252 \\
\hline & $S_{i}^{-}$ & 0.5301 & 0.4946 & 0.3769 & 0.3205 & 0.7269 \\
\hline & $\stackrel{l}{C}_{i}$ & 0.4378 & 0.4749 & 0.4463 & 0.506 & 0.5808 \\
\hline
\end{tabular}

Appendix A.6. Tomato Paste

Table A22. Pairwise comparisons matrix of tomato paste.

\begin{tabular}{ccccccccccc}
\hline $\begin{array}{c}\text { Tomato } \\
\text { Paste }\end{array}$ & $\mathbf{1}$ & $\mathbf{2}$ & $\mathbf{3}$ & $\mathbf{4}$ & $\mathbf{5}$ & $\mathbf{6}$ & $\mathbf{7}$ & $\mathbf{8}$ & $\mathbf{9}$ & $\mathbf{1 0}$ \\
\hline 1 & 1 & $1 / 9$ & $1 / 9$ & 7 & 5 & $1 / 9$ & 5 & 7 & 7 & 1 \\
2 & 9 & 1 & $1 / 5$ & 5 & 9 & 1 & $1 / 7$ & $1 / 5$ & 1 \\
3 & 9 & 5 & 1 & 1 & 3 & $1 / 7$ & 3 & 5 & 5 & 1 \\
4 & $1 / 7$ & $1 / 5$ & 1 & 1 & 5 & 1 & $1 / 7$ & 9 & 1 \\
5 & $1 / 5$ & $1 / 9$ & $1 / 3$ & $1 / 5$ & 1 & $1 / 5$ & $1 / 5$ & 5 & 3 & 3 \\
6 & 9 & 1 & 7 & 1 & 5 & 1 & 5 & $1 / 3$ & 5 & 5 \\
7 & $1 / 5$ & 7 & $1 / 3$ & 7 & 5 & $1 / 5$ & 1 & 1 & $1 / 3$ & 0.1 \\
8 & $1 / 7$ & 5 & $1 / 5$ & $1 / 9$ & $1 / 5$ & 3 & 1 & 1 & $1 / 3$ & 1 \\
9 & $1 / 7$ & 1 & $1 / 5$ & 1 & $1 / 3$ & $1 / 5$ & 3 & 3 & 1 & $1 / 9$ \\
10 & 1 & 1 & $1 / 3$ & $1 / 5$ & $1 / 3$ & $1 / 5$ & 7 & 1 & 9 \\
\hline
\end{tabular}

Table A23. Normalization matrix of tomato paste.

\begin{tabular}{cccccccccccc}
\hline $\begin{array}{c}\text { Tomato } \\
\text { Paste }\end{array}$ & $\mathbf{1}$ & $\mathbf{2}$ & $\mathbf{3}$ & $\mathbf{4}$ & $\mathbf{5}$ & $\mathbf{6}$ & $\mathbf{7}$ & $\mathbf{8}$ & $\mathbf{9}$ & $\mathbf{1 0}$ \\
\hline 1 & 0.034 & 0.005 & 0.01 & 0.298 & 0.148 & 0.016 & 0.196 & 0.215 & 0.214 & 0.049 \\
2 & 0.302 & 0.047 & 0.019 & 0.213 & 0.266 & 0.142 & 0.006 & 0.006 & 0.031 & 0.049 \\
3 & 0.302 & 0.233 & 0.093 & 0.043 & 0.089 & 0.02 & 0.118 & 0.154 & 0.153 & 0.148 \\
4 & 0.005 & 0.009 & 0.093 & 0.043 & 0.148 & 0.142 & 0.006 & 0.277 & 0.031 & 0.247 \\
5 & 0.007 & 0.005 & 0.031 & 0.009 & 0.03 & 0.028 & 0.008 & 0.154 & 0.092 & 0.148 \\
6 & 0.302 & 0.047 & 0.654 & 0.043 & 0.148 & 0.142 & 0.196 & 0.01 & 0.153 & 0.247 \\
7 & 0.007 & 0.327 & 0.031 & 0.298 & 0.148 & 0.028 & 0.039 & 0.031 & 0.01 & 0.007 \\
8 & 0.005 & 0.233 & 0.019 & 0.005 & 0.006 & 0.425 & 0.039 & 0.031 & 0.01 & 0.049 \\
9 & 0.005 & 0.047 & 0.019 & 0.043 & 0.01 & 0.028 & 0.118 & 0.092 & 0.031 & 0.005 \\
10 & 0.034 & 0.047 & 0.031 & 0.009 & 0.01 & 0.028 & 0.275 & 0.031 & 0.276 & 0.049 \\
\hline
\end{tabular}

Table A24. Weight of each criterion for tomato paste.

\begin{tabular}{ccccccccccc}
\hline $\begin{array}{c}\text { Tomato } \\
\text { Paste }\end{array}$ & $\mathbf{1}$ & $\mathbf{2}$ & $\mathbf{3}$ & $\mathbf{4}$ & $\mathbf{5}$ & $\mathbf{6}$ & $\mathbf{7}$ & $\mathbf{8}$ & $\mathbf{9}$ & $\mathbf{1 0}$ \\
\hline Weight & 0.119 & 0.108 & 0.135 & 0.100 & 0.051 & 0.194 & 0.093 & 0.082 & 0.040 & 0.079 \\
\hline
\end{tabular}

Now, the decision matrix for tomato paste is as follows: 
Table A25. Decision matrix considering suppliers and similarity index for tomato paste.

\begin{tabular}{|c|c|c|c|c|c|c|}
\hline \multirow{2}{*}{\multicolumn{2}{|c|}{ Suppliers }} & \multicolumn{5}{|c|}{ Tomato Paste } \\
\hline & & S1 & S2 & S3 & S4 & S5 \\
\hline \multirow{10}{*}{ Criteria } & 1 & $(3,5,7)$ & $(5,7,9)$ & $(1,3,5)$ & $(9,10,10)$ & $(1,3,5)$ \\
\hline & 2 & $(1,3,5)$ & $(3,5,7)$ & $(1,3,5)$ & $(5,7,9)$ & $(3,5,7)$ \\
\hline & 3 & $(9,10,10)$ & $(9,10,10)$ & $(1,3,5)$ & $(7,9,10)$ & $(3,5,7)$ \\
\hline & 4 & $(5,7,9)$ & $(5,7,9)$ & $(9,10,10)$ & $(5,7,9)$ & $(9,10,10)$ \\
\hline & 5 & $(3,5,7)$ & $(7,9,10)$ & $(7,9,10)$ & $(5,7,9)$ & $(7,9,10)$ \\
\hline & 6 & $(7,9,10)$ & $(1,3,5)$ & $(1,3,5)$ & $(9,10,10)$ & $(1,3,5)$ \\
\hline & 7 & $(1,3,5)$ & $(5,7,9)$ & $(9,10,10)$ & $(7,9,10)$ & $(1,3,5)$ \\
\hline & 8 & $(3,5,7)$ & $(5,7,9)$ & $(9,10,10)$ & $(1,3,5)$ & $(9,10,10)$ \\
\hline & 9 & $(7,9,10)$ & $(3,5,7)$ & $(1,3,5)$ & $(5,7,9)$ & $(5,7,9)$ \\
\hline & 10 & $(1,3,5)$ & $(5,7,9)$ & $(3,5,7)$ & $(3,5,7)$ & $(5,7,9)$ \\
\hline \multirow{3}{*}{ Variables } & $S_{i}^{+}$ & 0.3543 & 0.354 & 0.3261 & 0.4459 & 0.3603 \\
\hline & $S_{i}^{-}$ & 0.3543 & 0.2893 & 0.2713 & 0.4126 & 0.3119 \\
\hline & $\stackrel{l}{C}_{i}$ & 0.4845 & 0.4497 & 0.4542 & 0.4806 & 0.4641 \\
\hline
\end{tabular}

Appendix A.7. Lemon Juice

Table A26. Pairwise comparisons matrix of lemon juice.

\begin{tabular}{ccccccccccc}
\hline $\begin{array}{c}\text { Lemon } \\
\text { Juice }\end{array}$ & $\mathbf{1}$ & $\mathbf{2}$ & $\mathbf{3}$ & $\mathbf{4}$ & $\mathbf{5}$ & $\mathbf{6}$ & $\mathbf{7}$ & $\mathbf{8}$ & $\mathbf{9}$ & $\mathbf{1 0}$ \\
\hline 1 & 1 & 7 & 9 & $1 / 9$ & 7 & 5 & 9 & 3 & 9 & $1 / 9$ \\
2 & $1 / 7$ & 1 & 3 & 7 & 7 & 5 & 7 & $1 / 9$ & $1 / 9$ & $1 / 3$ \\
3 & $1 / 9$ & $1 / 3$ & 1 & 9 & 5 & 5 & $1 / 3$ & 3 & $1 / 9$ & $1 / 5$ \\
4 & 9 & $1 / 7$ & $1 / 9$ & 1 & 1 & 1 & $1 / 9$ & 1 & 1 & 9 \\
5 & $1 / 7$ & $1 / 7$ & $1 / 5$ & 1 & 1 & $1 / 7$ & 1 & $1 / 3$ & 5 & 3 \\
6 & $1 / 5$ & $1 / 5$ & $1 / 5$ & 1 & 7 & 1 & 9 & $1 / 7$ & 9 & 3 \\
7 & $1 / 9$ & $1 / 7$ & 3 & 9 & 1 & $1 / 9$ & 1 & $1 / 9$ & 3 & $1 / 3$ \\
8 & $1 / 3$ & 9 & $1 / 3$ & 1 & 3 & 7 & 9 & 1 & 3 & 7 \\
9 & $1 / 9$ & 1 & 9 & 1 & $1 / 5$ & $1 / 9$ & $1 / 3$ & $1 / 3$ & 1 & 5 \\
10 & 9 & 3 & 5 & $1 / 9$ & $1 / 3$ & $1 / 3$ & 3 & $1 / 7$ & $1 / 5$ & 1 \\
\hline
\end{tabular}

Table A27. Normalization matrix of lemon juice.

\begin{tabular}{ccccccccccc}
\hline $\begin{array}{c}\text { Lemon } \\
\text { Juice }\end{array}$ & $\mathbf{1}$ & $\mathbf{2}$ & $\mathbf{3}$ & $\mathbf{4}$ & $\mathbf{5}$ & $\mathbf{6}$ & $\mathbf{7}$ & $\mathbf{8}$ & $\mathbf{9}$ & $\mathbf{1 0}$ \\
\hline 1 & 0.034 & 0.005 & 0.01 & 0.298 & 0.148 & 0.016 & 0.196 & 0.215 & 0.214 & 0.049 \\
2 & 0.302 & 0.047 & 0.019 & 0.213 & 0.266 & 0.142 & 0.006 & 0.006 & 0.031 & 0.049 \\
3 & 0.302 & 0.233 & 0.093 & 0.043 & 0.089 & 0.02 & 0.118 & 0.154 & 0.153 & 0.148 \\
4 & 0.005 & 0.009 & 0.093 & 0.043 & 0.148 & 0.142 & 0.006 & 0.277 & 0.031 & 0.247 \\
5 & 0.007 & 0.005 & 0.031 & 0.009 & 0.03 & 0.028 & 0.008 & 0.154 & 0.092 & 0.148 \\
6 & 0.302 & 0.047 & 0.654 & 0.043 & 0.148 & 0.142 & 0.196 & 0.01 & 0.153 & 0.247 \\
7 & 0.007 & 0.327 & 0.031 & 0.298 & 0.148 & 0.028 & 0.039 & 0.031 & 0.01 & 0.007 \\
8 & 0.005 & 0.233 & 0.019 & 0.005 & 0.006 & 0.425 & 0.039 & 0.031 & 0.01 & 0.049 \\
9 & 0.005 & 0.047 & 0.019 & 0.043 & 0.01 & 0.028 & 0.118 & 0.092 & 0.031 & 0.005 \\
10 & 0.034 & 0.047 & 0.031 & 0.009 & 0.01 & 0.028 & 0.275 & 0.031 & 0.276 & 0.049 \\
\hline
\end{tabular}

Table A28. Weight of each criterion for lemon juice.

\begin{tabular}{lcccccccccc}
\hline $\begin{array}{l}\text { Lemon } \\
\text { Juice }\end{array}$ & $\mathbf{1}$ & $\mathbf{2}$ & $\mathbf{3}$ & $\mathbf{4}$ & $\mathbf{5}$ & $\mathbf{6}$ & $\mathbf{7}$ & $\mathbf{8}$ & $\mathbf{9}$ & $\mathbf{1 0}$ \\
\hline Weight & 0.192 & 0.103 & 0.105 & 0101 & 0.041 & 0.094 & 0.058 & 0.152 & 0.063 & 0.090 \\
\hline
\end{tabular}

Now, the decision matrix for lemon juice is as follows: 
Table A29. Weight of each criterion for lemon juice.

\begin{tabular}{|c|c|c|c|c|c|c|}
\hline \multicolumn{2}{|c|}{ Suppliers } & \multicolumn{5}{|c|}{ Lemon Juice } \\
\hline & & S1 & S2 & S3 & $\mathrm{S} 4$ & S5 \\
\hline \multirow{10}{*}{ Criteria } & 1 & $(3,5,7)$ & $(5,7,9)$ & $(5,7,9)$ & $(5,7,9)$ & $(9,10,10)$ \\
\hline & 2 & $(5,7,9)$ & $(9,10,10)$ & $(7,9,10)$ & $(9,10,10)$ & $(3,5,7)$ \\
\hline & 3 & $(7,9,10)$ & $(3,5,7)$ & $(7,9,10)$ & $(7,9,10)$ & $(1,3,5)$ \\
\hline & 4 & $(3,5,7)$ & $(3,5,7)$ & $(7,9,10)$ & $(9,10,10)$ & $(3,5,7)$ \\
\hline & 5 & $(7,9,10)$ & $(7,9,10)$ & $(1,3,5)$ & $(7,9,10)$ & $(3,5,7)$ \\
\hline & 6 & $(9,10,10)$ & $(1,3,5)$ & $(5,7,9)$ & $(5,7,9)$ & $(5,7,9)$ \\
\hline & 7 & $(7,9,10)$ & $(3,5,7)$ & $(7,9,10)$ & $(5,7,9)$ & $(1,3,5)$ \\
\hline & 8 & $(1,3,5)$ & $(7,9,10)$ & $(5,7,9)$ & $(1,3,5)$ & $(3,5,7)$ \\
\hline & 9 & $(7,9,10)$ & $(1,3,5)$ & $(7,9,10)$ & $(3,5,7)$ & $(9,10,10)$ \\
\hline & 10 & $(3,5,7)$ & $(7,9,10)$ & $(1,3,5)$ & $(3,5,7)$ & $(1,3,5)$ \\
\hline \multirow{3}{*}{ Variables } & $S_{i}^{+}$ & 0.2941 & 0.3466 & 0.366 & 0.2955 & 0.236 \\
\hline & $S_{i}^{-}$ & 0.4304 & 0.3502 & 0.4683 & 0.4596 & 0.1972 \\
\hline & $C_{i}$ & 0.594 & 0.5025 & 0.5613 & 0.6087 & 0.4551 \\
\hline
\end{tabular}

Appendix A.8. Tomato

Table A30. Pairwise comparisons matrix of tomato.

\begin{tabular}{ccccccccccc}
\hline Tomato & $\mathbf{1}$ & $\mathbf{2}$ & $\mathbf{3}$ & $\mathbf{4}$ & $\mathbf{5}$ & $\mathbf{6}$ & $\mathbf{7}$ & $\mathbf{8}$ & $\mathbf{9}$ & $\mathbf{1 0}$ \\
\hline 1 & 1 & $1 / 9$ & 1 & $1 / 7$ & $1 / 3$ & 1 & 1 & 1 & $1 / 9$ & 9 \\
2 & 9 & 1 & 5 & 1 & 7 & 3 & $1 / 9$ & $1 / 5$ & $1 / 5$ & 1 \\
3 & 1 & $1 / 5$ & 1 & 3 & 9 & 1 & $1 / 3$ & 5 & 5 & 7 \\
4 & 7 & 1 & $1 / 3$ & 1 & $1 / 9$ & $1 / 9$ & $1 / 7$ & 7 & 7 & 9 \\
5 & 3 & $1 / 7$ & $1 / 9$ & 9 & 1 & 3 & 9 & 1 & $1 / 5$ & $1 / 9$ \\
6 & 1 & $1 / 3$ & 1 & 9 & $1 / 3$ & 1 & $1 / 7$ & 1 & $1 / 7$ & 3 \\
7 & 1 & 9 & 3 & 7 & $1 / 9$ & 7 & 1 & $1 / 7$ & 9 & 7 \\
8 & 1 & 5 & $1 / 5$ & $1 / 7$ & 1 & 1 & 7 & 1 & 3 & 3 \\
9 & 9 & 5 & $1 / 5$ & $1 / 7$ & 5 & 7 & $1 / 9$ & $1 / 3$ & 1 & 1 \\
10 & $1 / 9$ & 1 & $1 / 7$ & $1 / 9$ & 9 & $1 / 3$ & $1 / 7$ & $1 / 3$ & 1 & 1 \\
\hline
\end{tabular}

Table A31. Normalization matrix of tomato.

\begin{tabular}{|c|c|c|c|c|c|c|c|c|c|c|}
\hline Tomato & 1 & 2 & 3 & 4 & 5 & 6 & 7 & 8 & 9 & 10 \\
\hline 1 & 0.03 & 0.005 & 0.083 & 0.005 & 0.01 & 0.041 & 0.053 & 0.059 & 0.004 & 0.219 \\
\hline 2 & 0.272 & 0.044 & 0.417 & 0.033 & 0.213 & 0.123 & 0.006 & 0.012 & 0.008 & 0.024 \\
\hline 3 & 0.03 & 0.009 & 0.083 & 0.098 & 0.274 & 0.041 & 0.018 & 0.294 & 0.188 & 0.17 \\
\hline 4 & 0.211 & 0.044 & 0.028 & 0.033 & 0.003 & 0.005 & 0.008 & 0.412 & 0.263 & 0.219 \\
\hline 5 & 0.091 & 0.006 & 0.009 & 0.295 & 0.03 & 0.123 & 0.474 & 0.059 & 0.008 & 0.003 \\
\hline 6 & 0.03 & 0.015 & 0.083 & 0.295 & 0.01 & 0.041 & 0.008 & 0.059 & 0.005 & 0.073 \\
\hline 7 & 0.03 & 0.395 & 0.25 & 0.229 & 0.003 & 0.286 & 0.053 & 0.008 & 0.338 & 0.17 \\
\hline 8 & 0.03 & 0.219 & 0.017 & 0.005 & 0.03 & 0.041 & 0.369 & 0.059 & 0.113 & 0.073 \\
\hline 9 & 0.272 & 0.219 & 0.017 & 0.005 & 0.152 & 0.286 & 0.006 & 0.02 & 0.038 & 0.024 \\
\hline 10 & 0.003 & 0.044 & 0.012 & 0.004 & 0.274 & 0.014 & 0.008 & 0.02 & 0.038 & 0.024 \\
\hline
\end{tabular}

Table A32. Weight of each criterion for tomato.

\begin{tabular}{ccccccccccc}
\hline Tomato & $\mathbf{1}$ & $\mathbf{2}$ & $\mathbf{3}$ & $\mathbf{4}$ & $\mathbf{5}$ & $\mathbf{6}$ & $\mathbf{7}$ & $\mathbf{8}$ & $\mathbf{9}$ & $\mathbf{1 0}$ \\
\hline Weight & 0.051 & 0.115 & 0.120 & 0.122 & 0.110 & 0.062 & 0.176 & 0.096 & 0.104 & 0.044 \\
\hline
\end{tabular}

Now, the decision matrix for tomato is as follows: 
Table A33. Decision matrix considering suppliers and similarity index for tomato.

\begin{tabular}{|c|c|c|c|c|c|c|}
\hline \multicolumn{2}{|c|}{ Suppliers } & \multicolumn{5}{|c|}{ Tomato } \\
\hline & & S1 & S2 & S3 & S4 & S5 \\
\hline \multirow{10}{*}{ Criteria } & 1 & $(5,7,9)$ & $(5,7,9)$ & $(3,5,7)$ & $(7,9,10)$ & $(7,9,10)$ \\
\hline & 2 & $(7,9,10)$ & $(9,10,10)$ & $(9,10,10)$ & $(1,3,5)$ & $(1,3,5)$ \\
\hline & 3 & $(7,9,10)$ & $(1,3,5)$ & $(5,7,9)$ & $(5,7,9)$ & $(9,10,10)$ \\
\hline & 4 & $(5,7,9)$ & $(3,5,7)$ & $(7,9,10)$ & $(7,9,10)$ & $(5,7,9)$ \\
\hline & 5 & $(3,5,7)$ & $(1,3,5)$ & $(5,7,9)$ & $(3,5,7)$ & $(1,3,5)$ \\
\hline & 6 & $(7,9,10)$ & $(3,5,7)$ & $(5,7,9)$ & $(7,9,10)$ & $(3,5,7)$ \\
\hline & 7 & $(7,9,10)$ & $(3,5,7)$ & $(7,9,10)$ & $(7,9,10)$ & $(5,7,9)$ \\
\hline & 8 & $(1,3,5)$ & $(3,5,7)$ & $(5,7,9)$ & $(3,5,7)$ & $(1,3,5)$ \\
\hline & 9 & $(9,10,10)$ & $(5,7,9)$ & $(9,10,10)$ & $(3,5,7)$ & $(7,9,10)$ \\
\hline & 10 & $(3,5,7)$ & $(9,10,10)$ & $(7,9,10)$ & $(3,5,7)$ & $(3,5,7)$ \\
\hline \multirow{3}{*}{ Variables } & $S_{i}^{+}$ & 0.3979 & 0.2829 & 0.3022 & 0.3359 & 0.542 \\
\hline & $S_{i}^{-}$ & 0.3038 & 0.2532 & 0.3623 & 0.3295 & 0.303 \\
\hline & $\stackrel{\iota}{C}_{i}$ & 0.433 & 0.4723 & 0.5452 & 0.4952 & 0.3586 \\
\hline
\end{tabular}

Appendix A.9. Yogurt

Table A34. Pairwise comparisons matrix of yogurt.

\begin{tabular}{ccccccccccc}
\hline Yogurt & $\mathbf{1}$ & $\mathbf{2}$ & $\mathbf{3}$ & $\mathbf{4}$ & $\mathbf{5}$ & $\mathbf{6}$ & $\mathbf{7}$ & $\mathbf{8}$ & $\mathbf{9}$ & $\mathbf{1 0}$ \\
\hline 1 & 1 & $1 / 9$ & 3 & 3 & 3 & 7 & $1 / 7$ & 3 & 5 & 9 \\
2 & 9 & 1 & 9 & 3 & 1 & 1 & 1 & $1 / 9$ & $1 / 7$ & 3 \\
3 & $1 / 3$ & $1 / 9$ & 1 & 1 & 3 & 9 & 1 & $1 / 7$ & $1 / 3$ & 1 \\
4 & $1 / 3$ & $1 / 3$ & 1 & 1 & 3 & 9 & $1 / 9$ & 3 & 3 & 3 \\
5 & $1 / 3$ & 1 & $1 / 3$ & $1 / 3$ & 1 & $1 / 7$ & $1 / 5$ & 7 & 5 & 3 \\
6 & $1 / 7$ & 1 & $1 / 9$ & $1 / 9$ & 7 & 1 & 1 & 3 & 3 & 5 \\
7 & 7 & 1 & 1 & 9 & 5 & 1 & 1 & 9 & 1 & 3 \\
8 & $1 / 3$ & 9 & 7 & $1 / 3$ & $1 / 7$ & $1 / 3$ & $1 / 9$ & 1 & 3 & 3 \\
9 & $1 / 5$ & 7 & 3 & $1 / 3$ & $1 / 5$ & $1 / 3$ & 1 & $1 / 3$ & 1 & 3 \\
10 & $1 / 9$ & $1 / 3$ & 1 & $1 / 3$ & $1 / 3$ & $1 / 5$ & $1 / 3$ & $1 / 3$ & $1 / 3$ & 1 \\
\hline
\end{tabular}

Table A35. Normalization matrix of yogurt.

\begin{tabular}{ccccccccccc}
\hline Yogurt & $\mathbf{1}$ & $\mathbf{2}$ & $\mathbf{3}$ & $\mathbf{4}$ & $\mathbf{5}$ & $\mathbf{6}$ & $\mathbf{7}$ & $\mathbf{8}$ & $\mathbf{9}$ & $\mathbf{1 0}$ \\
\hline 1 & 0.053 & 0.005 & 0.113 & 0.163 & 0.127 & 0.241 & 0.024 & 0.111 & 0.229 & 0.265 \\
2 & 0.479 & 0.048 & 0.34 & 0.163 & 0.042 & 0.034 & 0.17 & 0.004 & 0.007 & 0.088 \\
3 & 0.018 & 0.005 & 0.038 & 0.054 & 0.127 & 0.31 & 0.17 & 0.005 & 0.015 & 0.029 \\
4 & 0.018 & 0.016 & 0.038 & 0.054 & 0.127 & 0.31 & 0.019 & 0.111 & 0.138 & 0.088 \\
5 & 0.018 & 0.048 & 0.013 & 0.018 & 0.042 & 0.005 & 0.034 & 0.26 & 0.229 & 0.088 \\
6 & 0.008 & 0.048 & 0.004 & 0.006 & 0.296 & 0.034 & 0.17 & 0.111 & 0.138 & 0.147 \\
7 & 0.373 & 0.048 & 0.038 & 0.488 & 0.211 & 0.034 & 0.17 & 0.334 & 0.046 & 0.088 \\
8 & 0.018 & 0.431 & 0.265 & 0.018 & 0.006 & 0.011 & 0.019 & 0.037 & 0.138 & 0.088 \\
9 & 0.011 & 0.335 & 0.113 & 0.018 & 0.008 & 0.011 & 0.17 & 0.012 & 0.046 & 0.088 \\
10 & 0.006 & 0.016 & 0.038 & 0.018 & 0.014 & 0.007 & 0.057 & 0.012 & 0.015 & 0.029 \\
\hline
\end{tabular}

Table A36. Weight of each criterion for yogurt.

\begin{tabular}{ccccccccccc}
\hline Yogurt & $\mathbf{1}$ & $\mathbf{2}$ & $\mathbf{3}$ & $\mathbf{4}$ & $\mathbf{5}$ & $\mathbf{6}$ & $\mathbf{7}$ & $\mathbf{8}$ & $\mathbf{9}$ & $\mathbf{1 0}$ \\
\hline Weight & 0.133 & 0.138 & 0.077 & 0.092 & 0.075 & 0.096 & 0.183 & 0.103 & 0.081 & 0.021 \\
\hline
\end{tabular}

Now, the decision matrix for yogurt is as follows: 
Table A37. Decision matrix considering suppliers and similarity index for yogurt.

\begin{tabular}{|c|c|c|c|c|c|c|}
\hline \multicolumn{2}{|c|}{ Suppliers } & \multicolumn{5}{|c|}{ Yogurt } \\
\hline & & S1 & S2 & S3 & S4 & S5 \\
\hline \multirow{10}{*}{ Criteria } & 1 & $(7,9,10)$ & $(3,5,7)$ & $(7,9,10)$ & $(7,9,10)$ & $(5,7,9)$ \\
\hline & 2 & $(7,9,10)$ & $(3,5,7)$ & $(7,9,10)$ & $(9,10,10)$ & $(9,10,10)$ \\
\hline & 3 & $(1,3,5)$ & $(3,5,7)$ & $(3,5,7)$ & $(7,9,10)$ & $(5,7,9)$ \\
\hline & 4 & $(7,9,10)$ & $(3,5,7)$ & $(3,5,7)$ & $(1,3,5)$ & $(7,9,10)$ \\
\hline & 5 & $(3,5,7)$ & $(3,5,7)$ & $(5,7,9)$ & $(3,5,7)$ & $(7,9,10)$ \\
\hline & 6 & $(5,7,9)$ & $(1,3,5)$ & $(7,9,10)$ & $(1,3,5)$ & $(3,5,7)$ \\
\hline & 7 & $(3,5,7)$ & $(5,7,9)$ & $(1,3,5)$ & $(5,7,9)$ & $(1,3,5)$ \\
\hline & 8 & $(1,3,5)$ & $(7,9,10)$ & $(3,5,7)$ & $(7,9,10)$ & $(9,10,10)$ \\
\hline & 9 & $(5,7,9)$ & $(7,9,10)$ & $(7,9,10)$ & $(5,7,9)$ & $(7,9,10)$ \\
\hline & 10 & $(1,3,5)$ & $(9,10,10)$ & $(1,3,5)$ & $(3,5,7)$ & $(7,9,10)$ \\
\hline \multirow{3}{*}{ Variables } & $S_{i}^{+}$ & 0.2316 & 0.2642 & 0.2001 & 0.222 & 0.2196 \\
\hline & $S_{i}^{-}$ & 0.2171 & 0.2828 & 0.2139 & 0.2058 & 0.2207 \\
\hline & $\stackrel{\iota}{C}_{i}$ & 0.4839 & 0.517 & 0.5167 & 0.4811 & 0.5013 \\
\hline
\end{tabular}

\section{References}

1. Ghodsypour, S.H.; O'Brien, C. A decision support system for supplier selection using an integrated analytic hierarchy process and linear programming. Int. J. Prod. Econ. 1998, 56, 199-212. [CrossRef]

2. Hsu, C.W.; Hu, A.H. Applying hazardous substance management to supplier selection using analytic network process. J. Clean. Prod. 2009, 17, 255-264. [CrossRef]

3. Srivastava, S.K. Green supply-chain management: A state-of-the-art literature review. Int. J. Manag. Rev. 2007, 9, 53-80. [CrossRef]

4. Chen, C.T.; Lin, C.T.; Huang, S.F. A fuzzy approach for supplier evaluation and selection in supply chain management. Int. J. Prod. Econ. 2006, 102, 289-301. [CrossRef]

5. Junior, F.R.L.; Osiro, L.; Carpinetti, L.C.R. A comparison between Fuzzy AHP and Fuzzy TOPSIS methods to supplier selection. Appl. Soft Comput. 2014, 21, 194-209. [CrossRef]

6. Giacomarra, M.; Crescimanno, M.; Sakka, G.; Galati, A. Stakeholder engagement toward value co-creation in the F\&B packaging industry. EuroMed J. Bus. 2019, 15, 315-331.

7. Galati, A.; Giacomarra, M.; Concialdi, P.; Crescimanno, M. Exploring the feasibility of introducing Electric Freight Vehicles in the Short Food Supply Chain: A multi-stakeholder approach. Case Stud. Transp. Policy 2021. [CrossRef]

8. Paksoy, T.; Özceylan, E.; Weber, G.W. A multi objective model for optimization of a green supply chain network. In Proceedings of the AIP Conference Proceedings, Laurel, MD, USA, 23-25 February 2010; Volume 1239, pp. 311-320.

9. Paksoy, T.; Özceylan, E. Environmentally conscious optimization of supply chain networks. J. Oper. Res. Soc. 2014, 65, 855-872. [CrossRef]

10. Moslemi, S.; Sabegh, M.H.Z.; Mirzazadeh, A.; Ozturkoglu, Y.; Maass, E. A multi-objective model for multi-production and multi-echelon closed-loop pharmaceutical supply chain considering quality concepts: NSGAII approach. Int. J. Syst. Assur. Eng. Manag. 2017, 8, 1717-1733. [CrossRef]

11. Fazli-Khalaf, M.; Mirzazadeh, A.; Pishvaee, M.S. A robust fuzzy stochastic programming model for the design of a reliable green closed-loop supply chain network. Hum. Ecol. Risk Assess. Int. J. 2017, 23, 2119-2149. [CrossRef]

12. Razmi, J.; Babazadeh, R.; Kaviani, M.A. Optimisation of dynamic hydrogen supply chain network: A mathematical programming approach. Int. J. Appl. Manag. Sci. 2018, 10, 192-216. [CrossRef]

13. Banaeian, N.; Mobli, H.; Fahimnia, B.; Nielsen, I.E.; Omid, M. Green supplier selection using fuzzy group decision making methods: A case study from the agri-food industry. Comput. Oper. Res. 2018, 89, 337-347. [CrossRef]

14. Govindan, K.; Kadziński, M.; Sivakumar, R. Application of a novel PROMETHEE-based method for construction of a group compromise ranking to prioritization of green suppliers in food supply chain. Omega 2017, 71, 129-145. [CrossRef]

15. Validi, S.; Bhattacharya, A.; Byrne, P. Sustainable distribution system design: A two-phase DoE-guided meta-heuristic solution approach for a three-echelon bi-objective AHP-integrated location-routing model. Ann. Oper. Res. 2018, 290, 191-222. [CrossRef]

16. Liu, H.C.; Quan, M.Y.; Li, Z.; Wang, Z.L. A new integrated MCDM model for sustainable supplier selection under interval-valued intuitionistic uncertain linguistic environment. Inf. Sci. 2019, 486, 254-270. [CrossRef]

17. Chang, K.H. A novel supplier selection method that integrates the intuitionistic fuzzy weighted averaging method and a soft set with imprecise data. Ann. Oper. Res. 2019, 272, 139-157. [CrossRef]

18. Dickson, G.W. An analysis of vendor selection systems and decisions. J. Purch. 1966, 2, 5-17. [CrossRef] 
19. Lin, R.H. An integrated FANP-MOLP for supplier evaluation and order allocation. Appl. Math. Model. 2009, 33, $2730-2736$. [CrossRef]

20. Kannan, D.; Khodaverdi, R.; Olfat, L.; Jafarian, A.; Diabat, A. Integrated fuzzy multi criteria decision making method and multi-objective programming approach for supplier selection and order allocation in a green supply chain. J. Clean. Prod. 2013, 47, 355-367. [CrossRef]

21. Kumar, A.; Jain, V.; Kumar, S. A comprehensive environment friendly approach for supplier selection. Omega 2014, 42, 109-123. [CrossRef]

22. Bakeshlou, E.A.; Khamseh, A.A.; Asl, M.A.G.; Sadeghi, J.; Abbaszadeh, M. Evaluating a green supplier selection problem using a hybrid MODM algorithm. J. Intell. Manuf. 2017, 28, 913-927. [CrossRef]

23. Rueda, X.; Garrett, R.D.; Lambin, E.F. Corporate investments in supply chain sustainability: Selecting instruments in the agri-food industry. J. Clean. Prod. 2017, 142, 2480-2492. [CrossRef]

24. Shi, H.; Quan, M.Y.; Liu, H.C.; Duan, C.Y. A novel integrated approach for green supplier selection with interval-valued intuitionistic uncertain linguistic information: A case study in the agri-food industry. Sustainability 2018, 10, 733. [CrossRef]

25. Allaoui, H.; Guo, Y.; Choudhary, A.; Bloemhof, J. Sustainable agro-food supply chain design using two-stage hybrid multiobjective decision-making approach. Comput. Oper. Res. 2018, 89, 369-384. [CrossRef]

26. Gören, H.G. A decision framework for sustainable supplier selection and order allocation with lost sales. J. Clean. Prod. 2018, 183, 1156-1169. [CrossRef]

27. Liu, A.; Xiao, Y.; Ji, X.; Wang, K.; Tsai, S.B.; Lu, H.; Cheng, J.; Lai, X.; Wang, J. A novel two-stage integrated model for supplier selection of green fresh product. Sustainability 2018, 10, 2371. [CrossRef]

28. Haeri, S.A.S.; Rezaei, J. A grey-based green supplier selection model for uncertain environments. J. Clean. Prod. 2019, 221, 768-784. [CrossRef]

29. Tirkolaee, E.B.; Mardani, A.; Dashtian, Z.; Soltani, M.; Weber, G.W. A novel hybrid method using fuzzy decision making and multi-objective programming for sustainable-reliable supplier selection in two-echelon supply chain design. J. Clean. Prod. 2020, 250, 119517. [CrossRef]

30. Keshavarz-Ghorabaee, M.; Amiri, M.; Hashemi-Tabatabaei, M.; Zavadskas, E.K.; Kaklauskas, A. A New Decision-Making Approach Based on Fermatean Fuzzy Sets and WASPAS for Green Construction Supplier Evaluation. Mathematics 2020, 8, 2202. [CrossRef]

31. Tao, Q.; Huang, Z.; Gu, C.; Zhang, C. Optimization of green agri-food supply chain network using chaotic PSO algorithm. In Proceedings of the 2013 IEEE International Conference on Service Operations and Logistics, and Informatics, Dongguan, China, 28-30 July 2013; pp. 462-467.

32. Kannan, D.; Govindan, K.; Rajendran, S. Fuzzy axiomatic design approach based green supplier selection: A case study from Singapore. J. Clean. Prod. 2015, 96, 194-208. [CrossRef]

33. Amorim, P.; Curcio, E.; Almada-Lobo, B.; Barbosa-Póvoa, A.P.; Grossmann, I.E. Supplier selection in the processed food industry under uncertainty. Eur. J. Oper. Res. 2016, 252, 801-814. [CrossRef]

34. Govindan, K.; Sivakumar, R. Green supplier selection and order allocation in a low-carbon paper industry: Integrated multicriteria heterogeneous decision-making and multi-objective linear programming approaches. Ann. Oper. Res. 2016, 238, 243-276. [CrossRef]

35. Baek, S.H.; Kim, J.S. Efficient Algorithms for a Large-Scale Supplier Selection and Order Allocation Problem Considering Carbon Emissions and Quantity Discounts. Mathematics 2020, 8, 1659. [CrossRef]

36. Alavi, B.; Tavana, M.; Mina, H. A Dynamic Decision Support System for Sustainable Supplier Selection in Circular Economy. Sustain. Prod. Consum. 2021, 27, 905-920. [CrossRef]

37. Ghahtarani, A.; Najafi, A.A. Robust goal programming for multi-objective portfolio selection problem. Econ. Model. 2013, 33, 588-592. [CrossRef]

38. Saaty, T.L. The Analytic Hierarchy Process; McGraw-Hill: New York, NY, USA, 1980.

39. Saaty, T.L.; Vargas, L.G. Models, methods, concepts \& applications of the analytic hierarchy process. Interfaces 2012, $32,93$. [CrossRef]

40. Jäntschi, L. The eigenproblem translated for alignment of molecules. Symmetry 2019, 11, 1027. [CrossRef]

41. Plavka, J.; Gazda, M. Generalized eigenproblem of interval max-min (fuzzy) matrices. Fuzzy Sets Syst. 2021, 410, 27-44. [CrossRef]

42. Hanks, R.W.; Weir, J.D.; Lunday, B.J. Robust goal programming using different robustness echelons via norm-based and ellipsoidal uncertainty sets. Eur. J. Oper. Res. 2017, 262, 636-646. [CrossRef]

43. Ghasemi Bojd, F.; Koosha, H. A robust goal programming model for the capital budgeting problem. J. Oper. Res. Soc. 2018, 69, 1105-1113. [CrossRef]

44. Tirkolaee, E.B.; Mahmoodkhani, J.; Bourani, M.R.; Tavakkoli-Moghaddam, R. A self-learning particle swarm optimization for robust multi-echelon capacitated location-allocation-inventory problem. J. Adv. Manuf. Syst. 2019, 18, 677-694. [CrossRef]

45. Bertsimas, D.; Sim, M. Robust discrete optimization and network flows. Math. Program. 2003, 98, 49-71. [CrossRef]

46. Bertsimas, D.; Sim, M. The price of robustness. Oper. Res. 2004, 52, 35-53. [CrossRef]

47. Ben-Tal, A.; El Ghaoui, L.; Nemirovski, A. Robust Optimization; Princeton University Press: Princeton, NJ, USA, 2009.

48. Hatefi, S.M.; Jolai, F. Robust and reliable forward-reverse logistics network design under demand uncertainty and facility disruptions. Appl. Math. Model. 2014, 38, 2630-2647. [CrossRef] 
49. Govindan, K.; Rajendran, S.; Sarkis, J.; Murugesan, P. Multi criteria decision making approaches for green supplier evaluation and selection: A literature review. J. Clean. Prod. 2015, 98, 66-83. [CrossRef]

50. Shannon, C.E. A mathematical theory of communication. Bell Syst. Tech. J. 1948, 27, 379-423. [CrossRef]

51. Jäntschi, L.; Bolboacă, S.D. Informational entropy of B-ary trees after a vertex cut. Entropy 2008, 10, 576-588. [CrossRef]

52. Jäntschi, L.; Bolboacă, S.D. Performances of Shannon's entropy statistic in assessment of distribution of data. Ovidius Univ. Ann. Chem. 2017, 28, 30-42. [CrossRef]

53. Wu, J.; Sun, J.; Liang, L.; Zha, Y. Determination of weights for ultimate cross efficiency using Shannon entropy. Expert Syst. Appl. 2011, 38, 5162-5165. [CrossRef]

54. Bolboacă, S.D.; Jäntschi, L. Sensitivity, specificity, and accuracy of predictive models on phenols toxicity. J. Comput. Sci. 2014, 5, 345-350. [CrossRef]

55. Ahmad, M.H.; Ibrahim, M.I.; Mohamed, Z.; Ismail, N.; Abdullah, M.A.; Shueb, R.H.; Shafei, M.N. The sensitivity, specificity and accuracy of warning signs in predicting severe dengue, the severe dengue prevalence and its associated factors. Int. J. Environ. Res. Public Health 2018, 15, 2018. [CrossRef] [PubMed]

56. Roy, S.K.; Maity, G.; Weber, G.W. Multi-objective two-stage grey transportation problem using utility function with goals. Cent. Eur. J. Oper. Res. 2017, 25, 417-439. [CrossRef]

57. Goli, A.; Tirkolaee, E.B.; Aydin, N.S. Fuzzy integrated cell formation and production scheduling considering automated guided vehicles and human factors. IEEE Trans. Fuzzy Syst. 2021. [CrossRef]

58. Temoçin, B.Z.; Weber, G.W. Optimal control of stochastic hybrid system with jumps: A numerical approximation. J. Comput. Appl. Math. 2014, 259, 443-451. [CrossRef]

59. Kouhizadeh, M.; Saberi, S.; Sarkis, J. Blockchain technology and the sustainable supply chain: Theoretically exploring adoption barriers. Int. J. Prod. Econ. 2021, 231, 107831. [CrossRef] 